ARTICLE

\title{
Orexin receptors 1 and 2 in serotonergic neurons differentially regulate peripheral glucose metabolism in obesity
}

\author{
Xing Xiao (1) 1,2,3, Gagik Yeghiazaryann 3,4, Simon Hess 3,4, Paul Klemm (10) 1,2,3, Anna Sieben (10) 1,2,3, \\ André Kleinridders 1,2,3,5,10, Donald A. Morgan ${ }^{6}$, F. Thomas Wunderlich (1) 1,2,3, Kamal Rahmouni6, \\ Dong Kong (10 7,8, Thomas E. Scammell ${ }^{9}$, Bradford B. Lowell ${ }^{8}$, Peter Kloppenburg ${ }^{3,4}$, Jens C. Brüning (1) ${ }^{1,2,3,5}$ \& \\ A. Christine Hausen (10) 1,2,3凶
}

The wake-active orexin system plays a central role in the dynamic regulation of glucose homeostasis. Here we show orexin receptor type 1 and 2 are predominantly expressed in dorsal raphe nucleus-dorsal and -ventral, respectively. Serotonergic neurons in ventral median raphe nucleus and raphe pallidus selectively express orexin receptor type 1. Inactivation of orexin receptor type 1 in serotonin transporter-expressing cells of mice reduced insulin sensitivity in diet-induced obesity, mainly by decreasing glucose utilization in brown adipose tissue and skeletal muscle. Selective inactivation of orexin receptor type 2 improved glucose tolerance and insulin sensitivity in obese mice, mainly through a decrease in hepatic gluconeogenesis. Optogenetic activation of orexin neurons in lateral hypothalamus or orexinergic fibers innervating raphe pallidus impaired or improved glucose tolerance, respectively. Collectively, the present study assigns orexin signaling in serotonergic neurons critical, yet differential orexin receptor type 1- and 2-dependent functions in the regulation of systemic glucose homeostasis.

\footnotetext{
${ }^{1}$ Max Planck Institute for Metabolism Research, Department of Neuronal Control of Metabolism, Cologne, Germany. ${ }^{2}$ Center for Endocrinology, Diabetes and Preventive Medicine (CEDP), University Hospital Cologne, Cologne, Germany. ${ }^{3}$ Excellence Cluster on Cellular Stress Responses in Aging Associated Diseases (CECAD) and Center for Molecular Medicine Cologne (CMMC), University of Cologne, Cologne, Germany. ${ }^{4}$ Biocenter, Institute for Zoology, University of Cologne, Cologne, Germany. ${ }^{5}$ National Center for Diabetes Research (DZD), Neuherberg, Germany. ${ }^{6}$ Department of Neuroscience and Pharmacology, University of lowa, Carver College of Medicine, lowa City, IA, USA. ${ }^{7}$ Division of Endocrinology, Department of Pediatrics, F.M. Kirby Neurobiology Center, Boston Children's Hospital and Harvard Medical School, Boston, MA, USA. ${ }^{8}$ Division of Endocrinology, Diabetes and Metabolism, Department of Medicine, Beth Israel Deaconess Medical Center and Harvard Medical School, Boston, MA, USA. ${ }^{9}$ Department of Neurology, Beth Israel Deaconess Medical Center and Harvard Medical School, Boston, MA, USA. ${ }^{10}$ Present address: Institute of Nutritional Science, Department of Molecular and Experimental Nutritional Medicine, University of Potsdam, Nuthetal, Germany. ${ }^{{ }}$email: christine.hausen@sf.mpg.de
} 
T he obesity epidemic represents a major global socioeconomic burden, currently affecting over a third of the world's population ${ }^{1}$. However, the underlying cellular causes of weight gain and its associated metabolic comorbidities, such as type 2 diabetes mellitus, are still only poorly understood ${ }^{2}$. Orexins (hypocretins) are neuropeptides expressed by distinct neurons in the lateral hypothalamic area (LHA) and adjacent regions, including the perifornical area, and dorsomedial and posterior hypothalamus in humans and rodents ${ }^{3}$. The orexin system consists of the two distinct neuropeptides orexin- $\mathrm{A}$ and orexin-B (hypocretin-1 and -2), which are both derived from a common precursor peptide, and they act on two G-protein coupled receptors, orexin receptor type 1 (Ox1R) and type 2 $(\mathrm{Ox} 2 \mathrm{R})^{4,5}$. Human cerebrospinal fluid (CSF) orexin negatively correlates with serum glucose levels, and narcolepsy patients exhibit low orexin levels in CSF and increased obesity ${ }^{6,7}$. Ablation of orexin neurons in mice results in narcolepsy, hypoactivity, and late-onset obesity with or without hypophagia ${ }^{8,9}$. Mice that ubiquitously overexpress orexin show an increase in energy expenditure and are resistant to diet-induced obesity ${ }^{10}$. Interestingly, pharmacogenetic stimulation of orexin neurons results in an elevation of blood glucose levels with a simultaneous increase in locomotor activity and food intake ${ }^{11}$. The wake-active orexin system ${ }^{12}$ plays a key role in maintaining dynamic regulation and daily rhythm of peripheral glucose homeostasis, and it has been described to have dual roles in the regulation of blood glucose, possibly through the autonomic nervous system ${ }^{13,14}$.

Differential regulatory roles of Ox1R and Ox $2 \mathrm{R}$ in energy homeostasis and glucose metabolism throughout the organism have been revealed employing pharmacological or genetic methods. One study shows that Ox2R but not Ox1R predominantly mediates the orexin-overexpression-induced amelioration of obesity in mice fed a high-fat diet (HFD) ${ }^{10}$. In another study, Ox1R deficiency increases the body weight of mice fed a chow diet, but decreases intake of HFD and prevents HFDinduced excess of body weight gain, while Ox2R deficient mice mainly exhibited decreased energy expenditure ${ }^{15}$. Moreover, systemic histological studies have shown overlapping but distinct expressions of Ox1R and Ox2R in many brain regions, such as the cerebral neocortex, basal ganglia, hippocampus, thalamus, midbrain, and reticular formation ${ }^{16-18}$. Fasting increases Ox1R mRNA in the ventral medial hypothalamic nucleus, while Ox2R mRNA is increased in the arcuate nucleus of the hypothalamus ${ }^{19}$.

Interestingly, within a defined cell population of serotonergic neurons in raphe nuclei (RN), RNA sequencing (RNA-seq) experiments revealed that mainly Ox $2 \mathrm{R}$ but not Ox1R is differentially expressed among the subpopulations in dorsal raphe nucleus (DR), median raphe nucleus (MR) and caudal raphe nuclei including the raphe pallidus nucleus $(\mathrm{RPa})^{20}$. Serotonergic neurons in subregions of $\mathrm{RN}$ have been described as very heterogeneous in aspects of morphology, electrophysiological behavior, projections, and functions $\mathrm{s}^{20,21}$.

Importantly, the serotonergic system plays a central role in regulating wakefulness, appetite, glucose metabolism, and energy homeostasis ${ }^{22-25}$. Pharmacological experiments show that serotonin inhibits food intake and clinical drugs targeting the serotonergic system result in body weight $\operatorname{loss}^{26}$. In addition, ablation studies have demonstrated that central serotonergic cells activate and recruit thermogenic brown and beige fat and regulate glucose and lipid homeostasis ${ }^{27}$, and injection of orexin-A into $\mathrm{RPa}$ produces a sustained increase in brown adipose tissue (BAT) thermogenesis ${ }^{28}$.

In this work, we systematically investigated the expression and distribution of orexin receptors in serotonergic neurons in RN, and the impact of optogenetic activation of orexin signaling and specific inactivation of $\mathrm{Ox} 1 \mathrm{R}$ or $\mathrm{Ox} 2 \mathrm{R}$ signaling in serotonin transporter (Sert)-expressing cells on glucose metabolism and energy homeostasis. The present study assigns orexin signaling in serotonergic neurons critical, yet differential orexin receptor type 1- and 2-dependent functions in the regulation of systemic glucose homeostasis.

\section{Results}

Distribution of Ox1R and Ox2R expression in serotonergic neurons in RN. To systemically define the expression pattern of $\mathrm{Ox} 1 \mathrm{R}$ and $\mathrm{Ox} 2 \mathrm{R}$ in serotonergic neurons, Slc6a4-cre (Sert-Cre) mice were mated with tdTomato Flox (tdTomato fl/fl) mice to obtain Sert ${ }^{\text {tdTomato }}$ mice that express the red tomato (tdTomato) reporter protein upon Sert-Cre-mediated recombination of a loxP-flanked stop cassette ${ }^{29}$ specifically in serotonergic neurons. Beyond the raphe nuclei, ectopic expression of tdTomato was also detected in deep layers of the cingulate cortex $(\mathrm{Cg} 1$ and $\mathrm{Cg} 2)$, and ventral posterolateral (VPL), and ventral posteromedial (VPM) thalamic nuclei (Supplementary Fig. 1a-h). There were no detectable orexin receptors in tdTomato positive cells in these areas except for moderate expression levels of Ox $2 \mathrm{R}$ in the cingulate cortex, as revealed by fluorescent in situ hybridization (RNAscope) employing probes directed to tdTomato, Ox1R (Hcrtr1), and Ox2R (Hcrtr2) mRNA (Supplementary Fig. 1i, k). Most of the Ox2R signal could not be detected in tdTomato positive cells in the cingulate cortex, where only five cells out of the 45 tdTomato positive cells (10.74\%) expressed Ox2R (Supplementary Fig. 1j). As a positive control, abundant Ox1R and Ox2R mRNA was expressed in tdTomato positive neurons in DR (Supplementary Fig. 11). We further confirmed the specificity of Cre expression in raphe nuclei of a Sert ${ }^{\text {tdTomato mouse. As }}$ markers for serotonergic neurons, tryptophan hydroxylase isoform 2 (TPH2) and Pet1 were co-expressed by $94.90 \%$ or all of analyzed cells in DR and $\mathrm{RPa}$, respectively (Supplementary Fig. $1 \mathrm{~m}, \mathrm{n}, \mathrm{q})$. Here, almost all tdTomato positive neurons are TPH2 and/or Pet1 positive in DR, MR and RPa (Supplementary Fig. $1 \mathrm{~m}, \mathrm{p}, \mathrm{q}$ ). More than $95 \%$ of TPH2 and/or Pet1 positive neurons are tdTomato positive (Supplementary Fig. 1m, o, q, r). This indicates specific and efficient expression of Cre in serotonergic neurons in raphe nuclei.

The endogenous expression of $\mathrm{Ox} 1 \mathrm{R}$ and $\mathrm{Ox} 2 \mathrm{R}$ in serotonergic neurons in RN was systemically investigated in Sert ${ }^{\text {tdTomato }}$ mice. Ox1R was expressed in $66.01-89.20 \%$ of serotonergic neurons (tdTomato positive) in DR, MR, and RPa and the relative fluorescence signal in each neuron was strongest in DR-dorsal $(\mathrm{DRD}, \approx 1.86)$ compared to other regions $(\approx 0.64-0.92$; Fig. 1a-d). In contrast, $\mathrm{Ox} 2 \mathrm{R}$ was expressed in $63.43 \%$ of serotonergic neurons in DR-ventral (DRV), which was more than in DRD $(\approx 45.36 \%), \quad$ MR-dorsal $\quad(\mathrm{MRD}, \approx 28.18 \%), \quad$ MR-ventral (MRV, $\approx 13.94 \%)$ and $\mathrm{RPa}(\approx 22.94 \%$, Fig. 1a, b, e). The relative Ox2R fluorescence signal in each cell is also stronger in DRV $(\approx 2.66)$ compared to DRD $(\approx 1.33)$ and $\operatorname{MRD}(\approx 0.60$, Fig. 1a, b, f). Of note, the Ox2R signal in serotonergic neurons in MRV $(\approx 0.17)$ and $\mathrm{RPa}(\approx 0.24)$ was very weak (Fig. 1a, b, f).

Next, we analyzed published single-cell RNA sequencing (scRNA-seq) results of serotonergic neurons in $\mathrm{DR}^{30,31} \cdot 20.74 \%$ serotonergic neurons expressed Ox1R but not Ox2R (Ox1R-only), $6.25 \%$ serotonergic neurons expressed Ox2R but not Ox1R (Ox2Ronly), only $2.27 \%$ serotonergic neurons expressed both orexin receptors (Ox1R/Ox2R+), and $70.74 \%$ serotonergic neurons expressed none of the orexin receptors (Ox1R/Ox2R-) (Fig. 1g, g'). Interestingly, Slc17a8 (vesicular glutamate transporter 3, VGLUT3) was the only gene showing significantly different expression levels, comparing Ox1R-only with Ox2R-only serotonergic neurons (Source Data of Fig. 1i). The average expression level of VGLUT3 was higher in Ox2R-only than Ox1R-only 
a
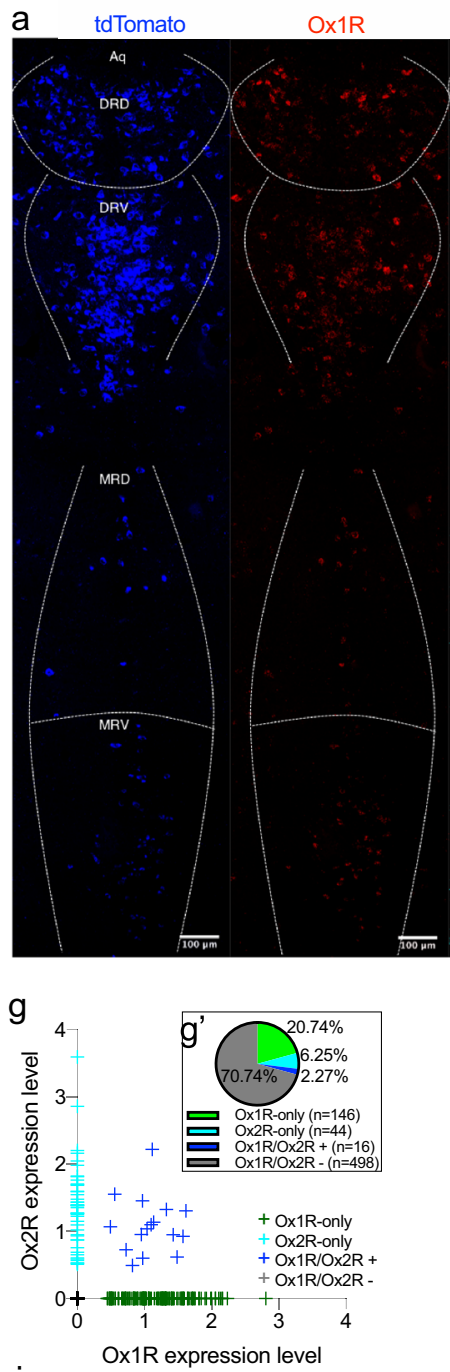

$\mathrm{O} 2 \mathrm{R}$

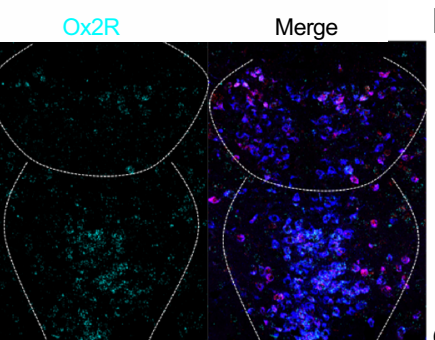

h

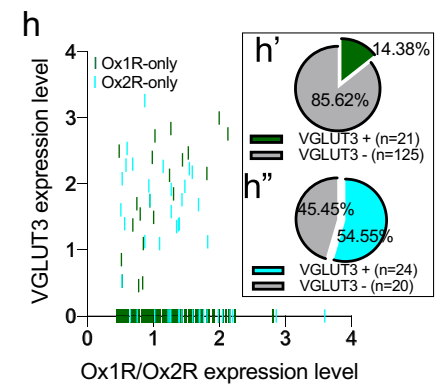
Ox1R/Ox2R expression level
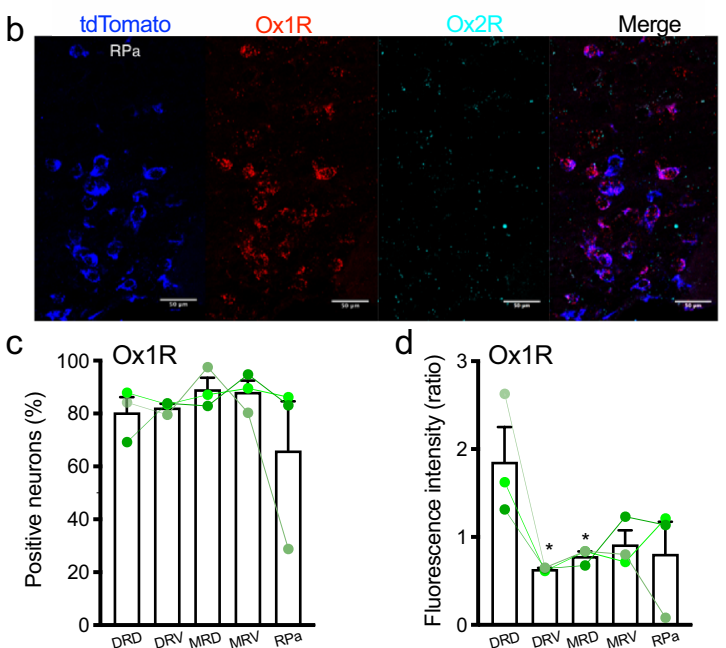

d
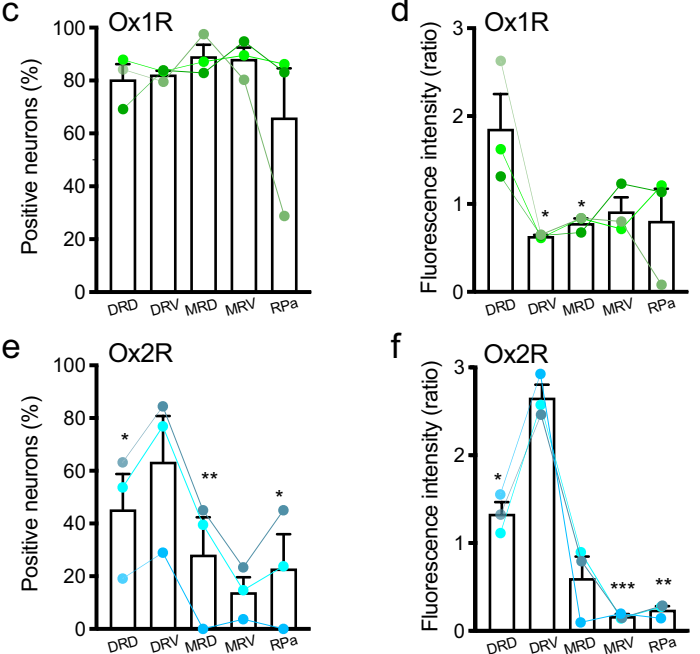

$\mathrm{f}$

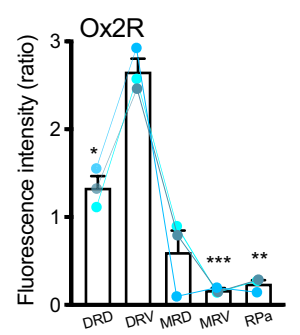

J

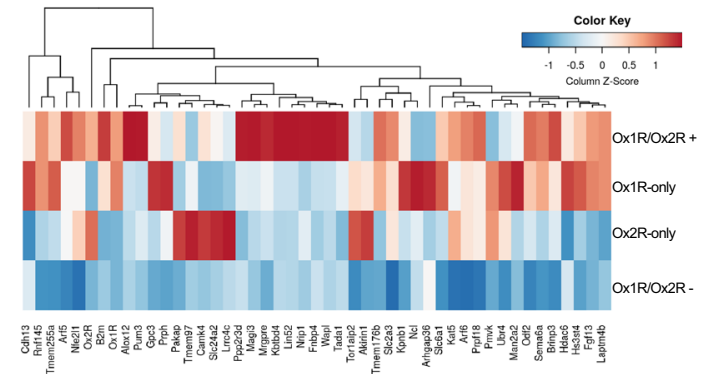

$\mathrm{k}$

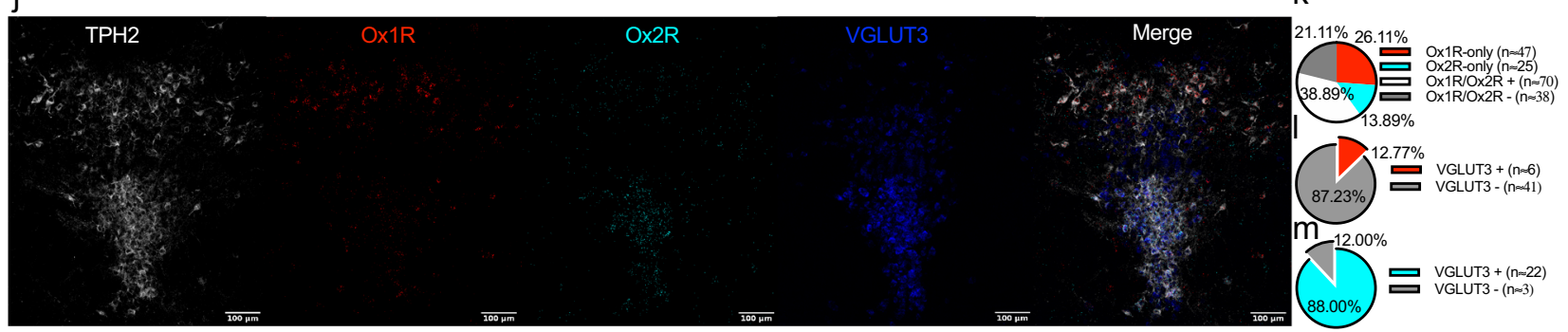

Fig. 1 Distribution of Ox1R and Ox2R in serotonergic neurons of the raphe nucleus of a SERTtdomato mouse. a Representative images of RNAscope in situ hybridization in the dorsal raphe nucleus (dorsal (DRD), ventral (DRV)), and median raphe nucleus (dorsal (MRD), ventral (MRV)). b Representative images of RNAscope in situ hybridization in the raphe pallidus (RPa). c, e Percentages of Ox1R or Ox2R positive neurons in serotonergic neurons. $\mathbf{d}, \mathbf{f}$ The average of relative fluorescence intensity of $\mathrm{Ox} 1 \mathrm{R}$ or $\mathrm{O} \times 2 \mathrm{R}$ signal in each serotonergic neuron. Fluorescence was normalized by the mean of all regions for each mouse. Blue, tdTomato; red, Ox1R; cyan, Ox2R. Scale bar: $100 \mu \mathrm{m}$ in (a) and $50 \mu \mathrm{m}$ in (b). $n=3$. Data are represented as means \pm SEM. d DRV: $p=0.035$, MRD: $p=0.036$; e DRD: $p=0.049$, MRD: $p=0.0081$, RPa: $p=0.028$; $\mathbf{D R D}: p=0.010$, MRV: $p=0.0008, \mathrm{RPa}: p=0.0099$. ${ }^{\star} p<0.05,{ }^{\star \star} p<0.01,{ }^{\star \star \star} p<0.001$; compared to DRD (d) or DRV $(\mathbf{e}, \mathbf{f})$, as determined by paired two-tailed $t$-test $(\mathbf{c}, \mathbf{e})$ or ratio paired two-tailed $t$-test (d, $\mathbf{f})$. Analysis of published scRNA-Seq data of serotonergic neurons in dorsal raphe nucleus (DR) ${ }^{30,31}: \mathbf{g}$ Scatter plot of raw cell read counts of Ox1R and Ox2 R, $\mathbf{g}^{\prime}$ percentages of serotonergic neurons only expressing Ox1R (Ox1R-only) or Ox2R (Ox2R-only) and those expressing both or none of Ox1R and Ox2R (Ox1/2R+ or Ox1/2R-), h scatter plot of raw vesicular glutamate transporter 3 (VGLUT3) counts against raw Ox1R or Ox2R counts, h' percentages of VGLUT3 positive $(+)$ and negative $(-)$ neurons in Ox1R-only and $\mathbf{h}$ " Ox2R-only serotonergic neurons, and $\mathbf{i}$ heat map of gene counts for cells with column-wise z-scores. Mean gene abundance was calculated per gene (x-dimension) and group (y-dimension). Column-wise $z$-scoring (per gene) was applied to make expression visually comparable between groups independent of average gene abundance levels. $\mathbf{j}$ Representative images of RNAscope in situ hybridization in the dorsal raphe nucleus (scale bar: $100 \mu \mathrm{m}$ ), and analysis: $\mathbf{k}$ percentages of Ox1R-only, Ox2R-only, Ox1/2R+ and Ox1/2R- serotonergic neurons; percentages of VGLUT3 positive neurons in (I) Ox1R-only and (m) Ox2R-only serotonergic neurons. Gray, tryptophan hydroxylase isoform 2 (TPH2); red, Ox1R; cyan, Ox2R; blue, VGLUT3. $n=3$. Source data are provided as a Source Data file. 
serotonergic neurons, mainly due to the fact that more Ox2R-only serotonergic neurons are VGLUT3 positive (Fig. 1h,h',h", Source Data of Fig. 1i). Further, we compared the gene expression patterns among Ox1R-only, Ox2R-only, Ox1R/Ox2R + (both positive), and Ox1R/Ox2R - (both negative) serotonergic neurons, and revealed 47 differently expressed genes (Fig. 1i, Source Data of Fig. 1i).

In scRNAseq analysis, the percentage of orexin-receptor-positive serotonergic neurons was lower than what we detected by RNAscope. Due to different sensitivity of detecting genes between scRNA-seq and RNAscope, Ox1R-only and Ox2R-only serotonergic neurons revealed by scRNA-seq could be similar to Ox1R- and Ox2R-dominant serotonergic neurons revealed by RNAscope. We further confirmed scRNAseq findings using RNAscope combined with TPH2 immunostaining, which revealed $26.11 \%$, $13.89 \%$, $38.89 \%$, and $21.11 \%$ Ox1R-only, Ox2R-only, Ox1R/Ox2R+ and Ox1R/Ox2R - serotonergic cells, respectively (Fig. 1j, k). VGLUT3 was mainly expressed in DRV, and more Ox2R-only serotonergic neurons are VGLUT3 positive $(88.00 \%)$ compared to Ox1R-only serotonergic neurons (12.77\%) (Fig. 1j, l, m).

Selective inactivation of $O x 1 R$ and $O x 2 R$ in serotonergic neurons in $\mathbf{R N}$. To specifically inactivate $\mathrm{Ox} 1 \mathrm{R}$ or $\mathrm{Ox} 2 \mathrm{R}$ in serotonergic neurons (Ox1R ${ }^{\Delta S E R T}, \mathrm{Ox}_{2} \mathrm{R}^{\Delta \mathrm{SERT}}$ ), Ox1R Flox (Ox1R fl/ $\mathrm{fl})$, and $\mathrm{Ox} 2 \mathrm{R}$ Flox $(\mathrm{Ox} 2 \mathrm{R} \mathrm{fl} / \mathrm{fl})$ mice were generated via homologous recombinant targeting in embryonic stem (ES) cells (Supplementary Fig. 2). The resulting animals were crossed with SertCre mice to obtain Ox1R fl/fl, Sert-Cre tg/wt mice (Ox1R $\left.{ }^{\Delta S E R T}\right)$, and $\mathrm{Ox} 2 \mathrm{R} \mathrm{fl} / \mathrm{fl}$, Sert-Cre tg/wt mice $\left(\mathrm{Ox} 2 \mathrm{R}^{\Delta \mathrm{SERT}}\right)$. Mice from the same breeding without the Cre transgene were used as controls (Ox1R fl/fl, Sert-Cre wt/wt or Ox2R fl/fl, Sert-Cre wt/wt mice). Ox $1 R^{\triangle S E R T}$ or Ox $2 R^{\triangle S E R T}$ mice were further intercrossed with Ox1R fl/fl, tdTomato $\mathrm{fl} / \mathrm{fl}$ mice or Ox2R fl/fl, tdTomato $\mathrm{fl} / \mathrm{fl}$ mice, respectively, to obtain $\mathrm{Ox} 1 \mathrm{R} \mathrm{fl} / \mathrm{fl}$, tdTomato $\mathrm{fl} /-$, Sert-Cre tg/wt $\left(\mathrm{Ox} 1 \mathrm{R}^{\Delta \mathrm{SERT} / \mathrm{tdTomato}}\right)$ mice or Ox2R fl/fl, tdTomato $\mathrm{fl} /-$, Sert-Cre tg/wt (Ox $2 \mathrm{R}^{\Delta \mathrm{SERT} / \mathrm{tdTomato})}$ mice that express tdTomato but lack $\mathrm{Ox} 1 \mathrm{R}$ or $\mathrm{Ox} 2 \mathrm{R}$ in serotonergic neurons.

In $\mathrm{Ox} 1 \mathrm{R}^{\Delta \mathrm{SERT} / \mathrm{tdTomato}}$ or $\mathrm{Ox} 2 \mathrm{R}^{\Delta \mathrm{SERT} / \mathrm{tdT} \text { Tomato mice, we }}$ confirmed the specific deletion of Ox1R or Ox $2 \mathrm{R}$, respectively, in serotonergic neurons in $\mathrm{RN}$ via RNAscope detection of tdTomato, Ox1R, and Ox2R mRNA. In Ox1R ${ }^{\Delta S E R T / t d T o m a t o ~}$ mice, the Ox1R signal was almost completely abrogated in serotonergic neurons and only single-labeled, non-Sert Ox1Rexpressing cells were observed, while the Ox2R signal exhibited a similar expression pattern to that in the Sert tdTomato mice

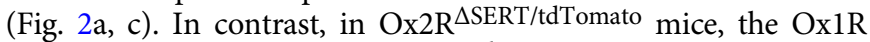
signal was similar to that in the Sert ${ }^{\text {tdTomato }}$ mice, while the Ox2R signal almost disappeared in serotonergic neurons and some single-labeled, non-Sert Ox2R-expressing cells were observed (Fig. 2b, d). Accordingly, Ox1R ${ }^{\Delta S E R T / t d T o m a t o ~ m i c e ~ s h o w e d ~}$ significantly lower percentages of $\mathrm{Ox} 1 \mathrm{R}$ positive neurons in serotonergic neurons and also significantly lower raw fluorescence intensity of Ox1R signal in individual serotonergic neurons in all $\mathrm{RN}$ regions compared to $\mathrm{Ox} 2 \mathrm{R}^{\Delta \mathrm{SERT} / \mathrm{tdT} \text { mato }}$ mice (Fig. 2e, f).

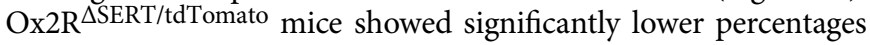
of $\mathrm{Ox} 2 \mathrm{R}$ positive neurons in serotonergic neurons in $\mathrm{DRD}, \mathrm{DRV}$, and MRD and also significantly lower raw fluorescence intensity of Ox2R signal in individual serotonergic neurons in DRD and DRV than Ox1R ${ }^{\triangle S E R T / t d T o m a t o}$ mice (Fig. $2 g, h$ ). In

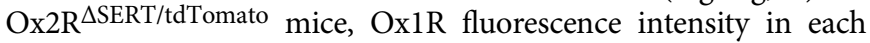
$\mathrm{DRD}$ serotonergic neuron was highest among all $\mathrm{RN}$ regions and significantly higher than that in DRV, MRD, and MRV (Fig. 2f). In Ox1R ${ }^{\Delta S E R T / t d T o m a t o ~ m i c e, ~ O x 2 R ~ m R N A ~ e x p r e s s i o n ~ l e v e l s ~ i n ~}$ serotonergic neurons in DRV were highest and significantly higher than levels in MRD, MRV, and RPa, as quantified in percentages of positive neurons and raw fluorescent intensity (Fig. $2 \mathrm{~g}, \mathrm{~h}$ ).
Notably, in serotonergic neurons in MRV and $\mathrm{RPa}, \mathrm{Ox} 2 \mathrm{R}$ mRNA expression levels were similar between $\mathrm{Ox} 1 \mathrm{R}^{\Delta \mathrm{SERT} / \mathrm{tdTomato}}$ mice and $\mathrm{O} 2 \mathrm{R}^{\Delta \mathrm{SERT} / \mathrm{tdTomato}}$ mice, which indicates that this signal was close to the background fluorescence related to method limitations, presumably (Fig. 2g, h). Therefore, only Ox1R but not Ox2R was detectable in serotonergic neurons in MRV and RPa.

Differential activation of DR serotonergic neurons by orexin. To further validate the deletion of orexin receptor signaling, we performed perforated patch-clamp recordings and $\mathrm{Ca}^{2+}$ imaging on DR serotonergic neurons from control, Ox $1 R^{\Delta S E R T}$, and $\mathrm{Ox} 2 \mathrm{R}^{\triangle \mathrm{SERT}}$ mice with tdTomato reporter or genetically encoded calcium indicator GCaMP6 in serotonergic neurons (Fig. 3a-e). During the experiments, GABAergic and glutamatergic synaptic input was blocked.

In the first series of experiments we performed patch-clamp recordings in the DR with the focus mainly on the DRD. $100 \mathrm{nM}$ orexin A increased the action potential firing rate in control serotonergic neurons $(p<0.0001, \mathrm{n}=21$; Fig. $3 \mathrm{~b})$, which is in line with previous studies ${ }^{32-34}$. Similarly, $100 \mathrm{nM}$ orexin A increased the activity of serotonergic neurons in Ox1R ${ }^{\Delta S E R T / t d T o m a t o ~}$ $(p<0.05, n=9 ; \quad$ Fig. $3 \mathrm{~b})$ and $\mathrm{Ox} 2 \mathrm{R}^{\Delta \text { SERT/tdTomato mice }}$ $(p<0.005, n=11$; Fig. 3b). In contrast, $100 \mathrm{nM}$ orexin B increased action potential firing rate only in control $(p<0.0001$, $n=27$; Fig. $3 c)$ and Ox1R $\Delta$ SERT/tdTomato mice $(p<0.0001, n=14$;

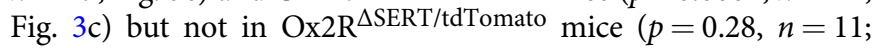
Fig. 3c). A representative recording with response to 1,10 , and $100 \mathrm{nM}$ of orexin $\mathrm{A}$ in a control neuron was shown in Supplementary Fig. 3a, b.

In the second series of experiments we focused on the analysis of serotonergic neurons in the DRV using $\mathrm{Ca}^{2+}$ imaging with the genetically encoded calcium indicator GCaMP6 (Fig. 3d, e). $100 \mathrm{nM}$ orexin A increased $\left[\mathrm{Ca}^{2+}\right]_{\mathrm{i}}$ in control $(p<0.0001$, $n=159), \operatorname{Ox} 1 \mathrm{R}^{\Delta \text { SERT }}(p<0.0001, n=200)$ and Ox $2 \mathrm{R}^{\Delta \text { SERT }}$ neurons $(p<0.0001, n=75)$. The increase in $\left[\mathrm{Ca}^{2+}\right]_{\mathrm{i}}$ was significantly smaller in $\mathrm{Ox} 2 \mathrm{R}^{\Delta \mathrm{SERT}}$ neurons compared to control $(p<0.0001)$ and Ox1R ${ }^{\triangle S E R T}(p<0.0001)$ neurons. $100 \mathrm{nM}$ orexin $\mathrm{B}$ increased $\left[\mathrm{Ca}^{2+}\right]_{\mathrm{i}}$ in control $(p<0.0001, n=75)$ and Ox1R $\mathrm{R}^{\Delta \text { SERT }}$ neurons $(p<0.0001, n=92)$ and had no effect on Ox2R ${ }^{\Delta \text { SERT }}$ neurons $(p=0.8, n=122)$.

The differential and complex response patterns are likely caused by the differences in affinity profiles of orexin $A$ and orexin $\mathrm{B}$ to $\mathrm{Ox} 1 \mathrm{R}$ and $\mathrm{Ox} 2 \mathrm{R}^{4}$, and the varying rate of $\mathrm{Ox} 1 \mathrm{R}$ and $\mathrm{Ox} 2 \mathrm{R}$ expression in different regions of the $\mathrm{DR}$ as described above. In radioligand binding assays, orexin- $\mathrm{A}$ had high affinities to $\mathrm{Ox} 1 \mathrm{R}\left(\mathrm{IC}_{50}=20 \mathrm{nM}\right)$ as well as to $\mathrm{Ox} 2 \mathrm{R}\left(\mathrm{IC}_{50}=38 \mathrm{nM}\right)$, whereas orexin $\mathrm{B}$ has a high affinity to $\mathrm{Ox} 2 \mathrm{R}\left(\mathrm{IC}_{50}=36 \mathrm{nM}\right)$ and only a low affinity to Ox1R $\left(\mathrm{IC}_{50}=420 \mathrm{nM}\right)^{4}$. While both orexin receptors are expressed in the DRD and the DRV, the relative expression of Ox1R is higher in the DRD, whereas the relative expression of $\mathrm{Ox} 2 \mathrm{R}$ is higher in the DRV (Fig. 1a, $d-f$ ).

Since orexin-A is highly affine to both receptors, orexin A increases activity in serotonergic DRD neurons of Ox $1 \mathrm{R}^{\Delta \mathrm{SERT} / \mathrm{tdT} \text { Tomato }}$ and Ox $2 \mathrm{R}^{\Delta \mathrm{SERT} / \text { tdTomato mice, even when }}$ one receptor is switched off. The effect of Ox1R deletion becomes only detectable at very low orexin A concentrations (Supplementary Fig. 3c) since the affinity of orexin A is higher to Ox1R than to Ox2R. Orexin B, in contrast, has only a low affinity for OxR1. Thus, when $\mathrm{Ox} 2 \mathrm{R}$ are switched off, the neurons do not react anymore (Fig. 3c). In the DRV, the situation is different in the sense that $\mathrm{Ox} 2 \mathrm{R}$ are relatively higher expressed than Ox1R. If $\mathrm{Ox} 2 \mathrm{R}$ are missing, there are too few receptors to fully activate the serotonergic neurons of the DRV with orexin A. In the absence of $\mathrm{Ox} 2 \mathrm{R}$, orexin $\mathrm{B}$ can practically no longer trigger an effect due to its low affinity to Ox1R. 
a

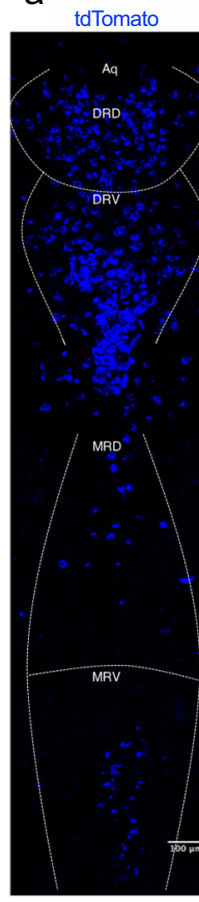

C

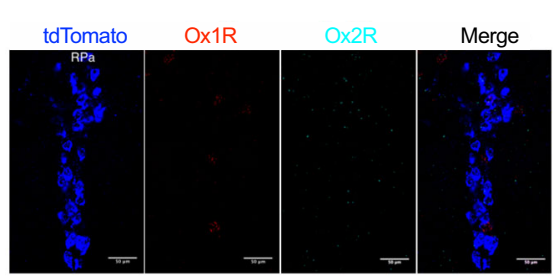

d

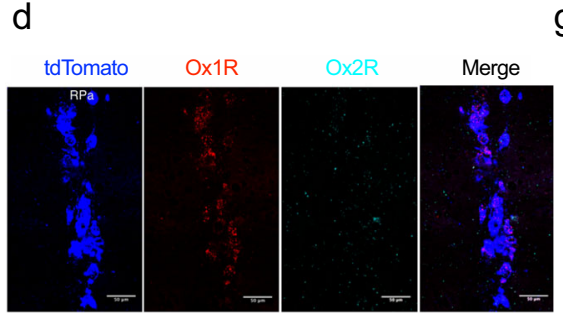

Ox1R

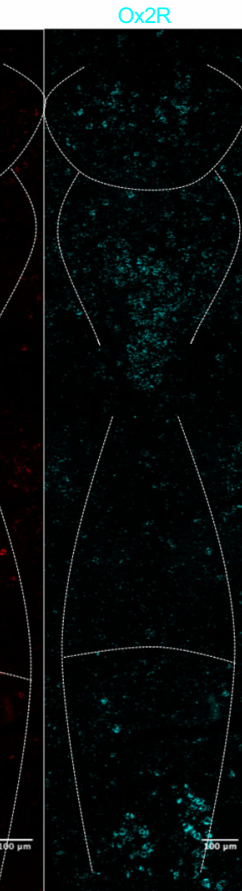

e

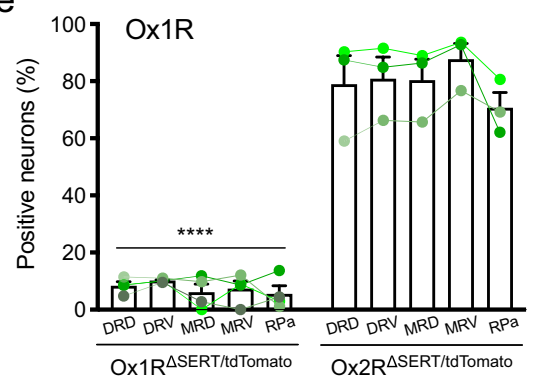

Merge

b

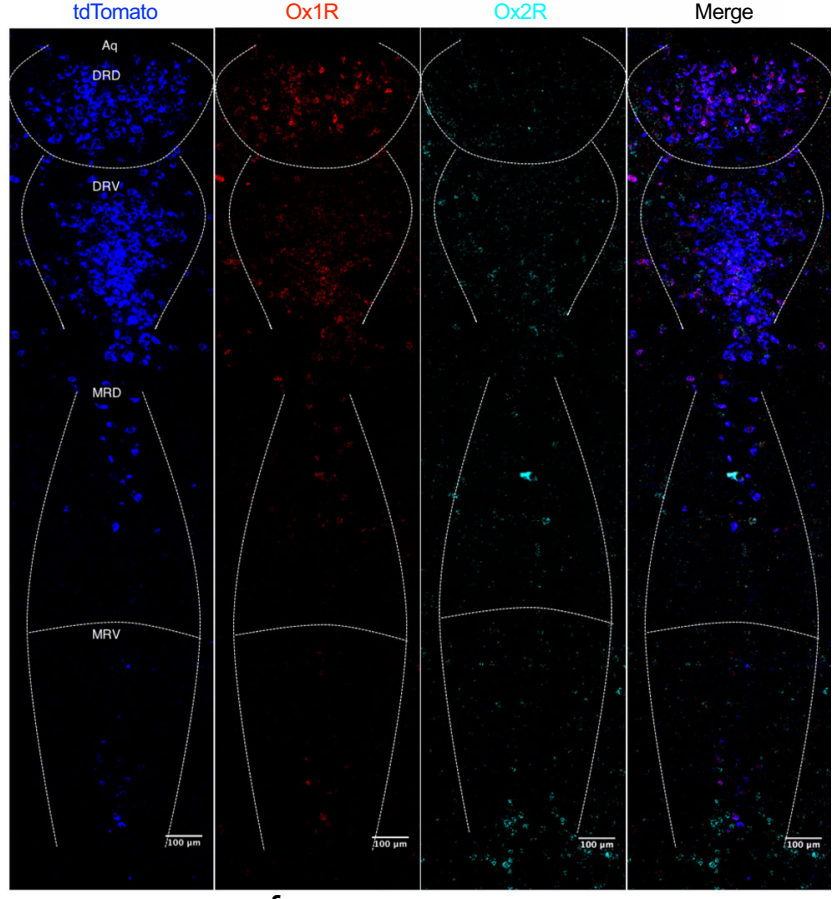

f

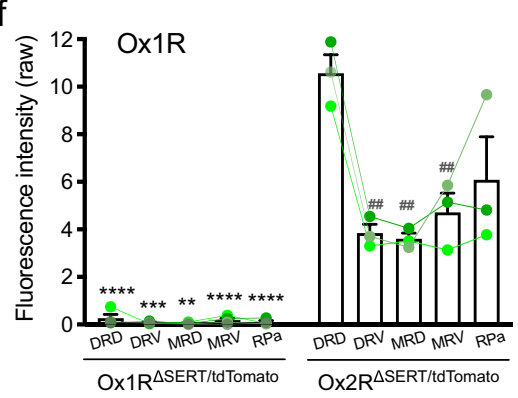

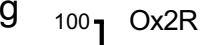

$\mathrm{h}$

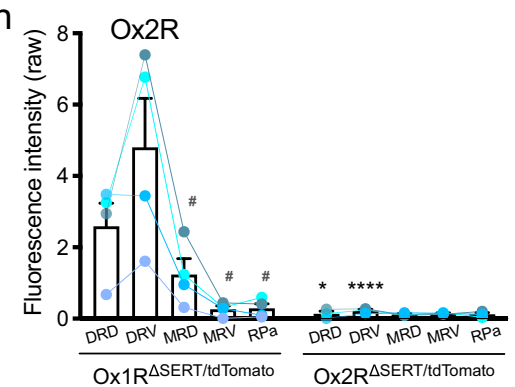

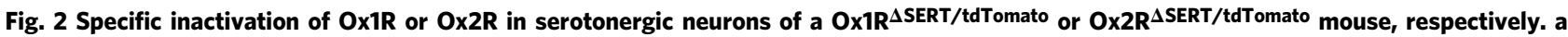

Representative images of RNAscope in situ hybridization in the dorsal raphe nucleus (dorsal (DRD), ventral (DRV)) and median raphe nucleus (dorsal (MRD), ventral (MRV)) of a Ox1R $\triangle$ SERT/tdTomato mouse and $\mathbf{b}$ a Ox2R $\triangle$ SERT/ tdTomato mouse. $\mathbf{c}$ Representative images of RNAscope in situ hybridization in the raphe pallidus (RPa) of a Ox1R ${ }^{\Delta S E R T / t d T o m a t o ~ m o u s e ~ a n d ~} \mathbf{d}$ a Ox $2 R^{\Delta S E R T / t d T o m a t o ~ m o u s e . ~ e, ~} \mathbf{g}$ Percentages of Ox1R or Ox $2 R$ positive neurons in serotonergic neurons. $\mathbf{f}$, h The average of raw fluorescence intensity of Ox1R or Ox2R signal in each serotonergic neuron. Blue, tdTomato; red, Ox1R; cyan, Ox2R. Scale bar: $100 \mu \mathrm{m}$ in (a, b) and $50 \mu \mathrm{m}$ in (c, d). Ox1R $\Delta$ SERT/tdTomato, $n=4$; Ox2R ${ }^{S E R T} /$ tdTomato, $n=3$. Data are represented as means \pm SEM. $\mathbf{f}$ Ox1R $\Delta$ SERT/tdTomato: $p=0.0005$ (DRV) and 0.0011 (MRD); Ox2R $\Delta$ SERT/ tdTomato: $p=0.0041$ (DRV), 0.0088 (MRD) and 0.0098 (MRV). $\mathbf{g}$ Ox1R $\Delta$ SERT/ tdTomato: $p=0.013$ (MRD), 0.0006 (MRV) and 0.0014 (RPa); Ox2R $\triangle$ SERT/ tdTomato: $p=0.0002$ (DRD) and 0.0046 (MRD). h Ox1R $\Delta$ SERT/ tdTomato: $p=0.038$ (MRD), 0.039 (MRV) and 0.037 (RPa); Ox2R ${ }^{\Delta S E R T / \text { tdTomato: }} p=0.037$ (DRD). ${ }^{\star} p<0.05,{ }^{\star \star} p<0.01,{ }^{\star \star \star} p<0.001,{ }^{\star \star \star \star} p<0.0001$; as determined by two-way ANOVA followed by Sidak's post hoc test. The main effect of genotype: e $(F(1,25)=583.60, p<0.0001), \mathbf{f}(F(1,25)=234.20, p<0.0001), \mathbf{g}(F(1,25)=53.99, p<0.0001), \mathbf{h}(F(1,25)=20.08$, $p=0.0001) .{ }^{\#} p<0.05,{ }^{\#} p<0.01,{ }^{\# \#} p<0.001$, compared to DRD $(\mathbf{f})$ or DRV $(\mathbf{g}, \mathbf{h})$, as determined by paired two-tailed $t$-test. Source data are provided as a Source Data file.

Orexin neurons are activated in HFD-induced obesity. In order to investigate the activation of orexin neurons in lean and obese mice, we compared c-Fos expression in orexin neurons in $6 \mathrm{~h}$-fasted BL/6 mice, which had been fed a HFD for 10 weeks since weaning, to that in mice exposed for the same period to a control diet (CD). To this end, we determined the expression of orexin (Hcrt) and c-Fos (Fos) mRNA via RNAscope hybridization. This analysis revealed, that the proportion of c-Fos-expressing orexin neurons in the $\mathrm{LH}$ was 
a
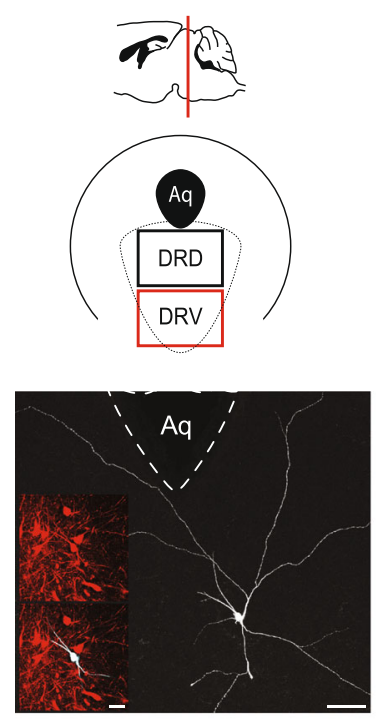

b
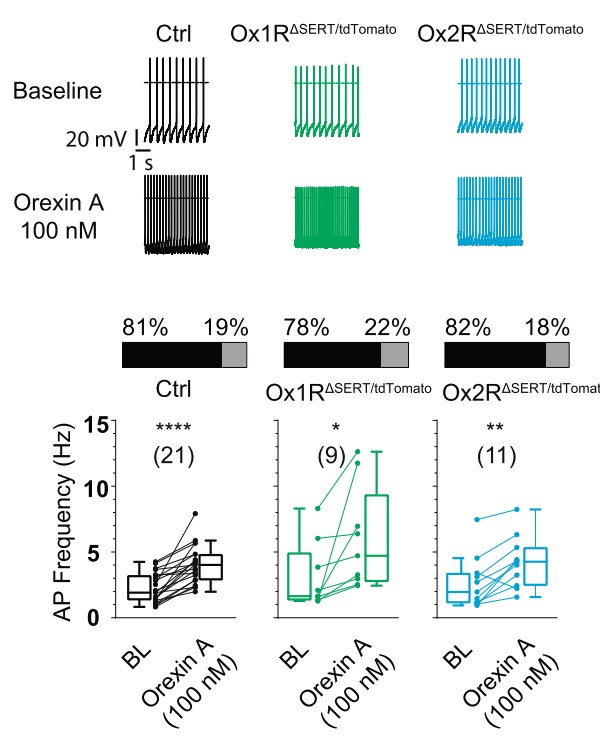

c

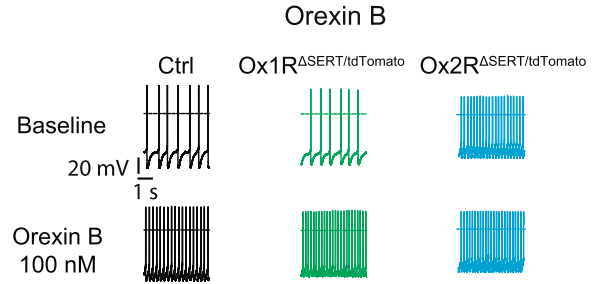

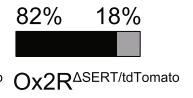

(11)

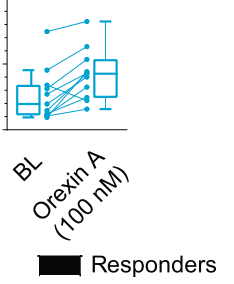

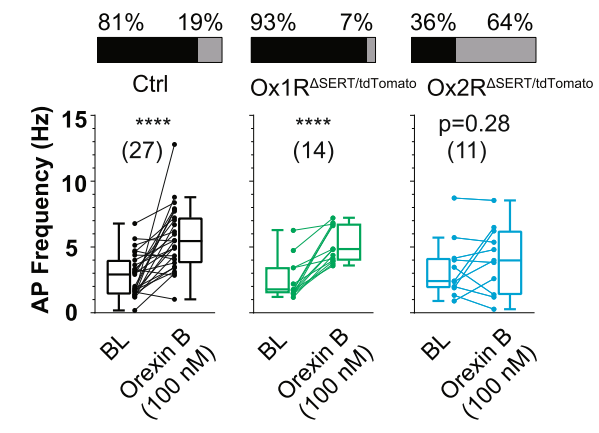

Non-responders

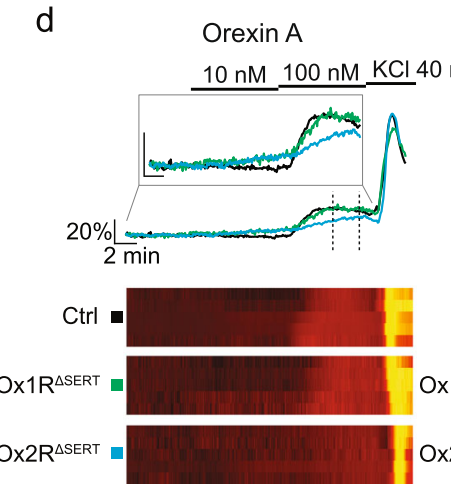

Orexin A

Orexin B

$10 \mathrm{nM} 100 \mathrm{nM} \mathrm{KCl} 40 \mathrm{mM}$ e
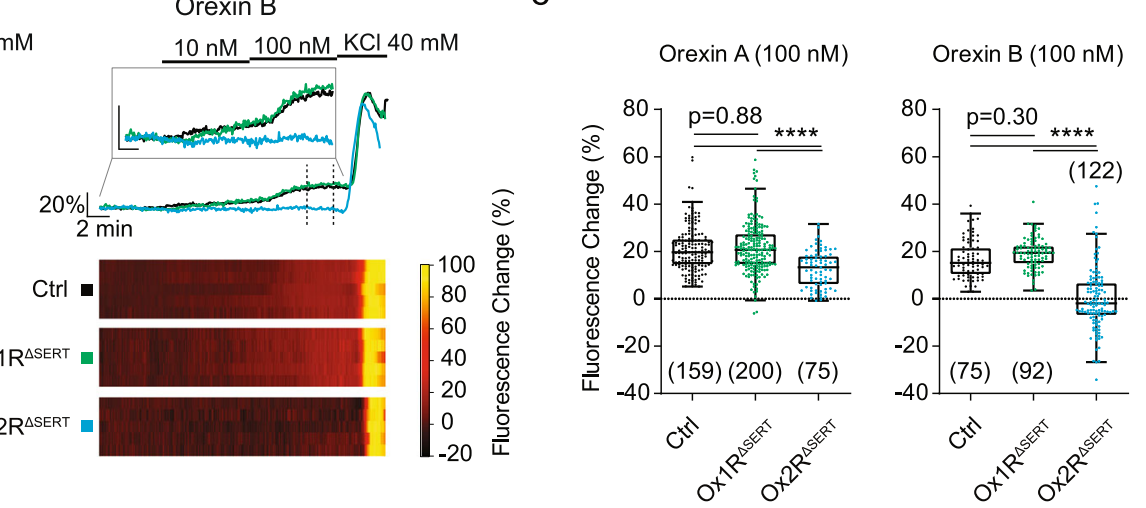

Fig. 3 Effect of orexin A and orexin B on serotonergic neurons in the dorsal raphe nucleus (DR) analyzed by patch-clamp recordings and $\mathrm{Ca}^{2}+{ }^{2}$ imaging with GCaMP6. Recordings were performed in brain slices from control, Ox1R ${ }^{\triangle S E R T}$, and Ox2R $\mathrm{R}^{\triangle \mathrm{SERT}}$ male mice, with tdTomato or GCaMP6 expression in serotonergic neurons for patch clamp or $\mathrm{Ca}^{2}+$ imaging, respectively. a Schematic illustration of the dorsal raphe nucleus (dorsal (DRD), ventral (DRV)) and an exemplary image of a recorded serotonergic neuron in DRD, which was biocytin-streptavidin labeled during the experiment. Scale bar: $50 \mu \mathrm{m}$. Insert: tdTomato labeling (top) and double labeling with tdTomato and biocytin-streptavidin (bottom). Scale bar: $20 \mu \mathrm{m}$. b, c Orexin A (b) and orexin B (c) effect on action potential firing rate of serotonergic neurons in DRD. Original recordings (top) and comparisons of mean firing rates (bottom). The stacked bars show the percentage of individual neurons in which the increase in action potential frequency was larger than $3 \times$ SD of the control, thus defining them as responsive (see "Methods"). Mean firing rates were compared using paired two-tailed students $t$-test. b Orexin A application: Ctrl, $p<0.0001, n=21$; Ox1R ${ }^{\Delta E R T}: p=0.03, n=9 ;$ Ox2R $\triangle$ SERT: $p=0.0018, n=11$. c Orexin B application: Ctrl, $p<0.0001, n=27 ;$ Ox1R $\Delta$ SERT: $p<0.0001, n=14 ;$ Ox2R ${ }^{\Delta S E R T:}$ $p=0.28, n=11$. Abbreviation: baseline (BL). d, e Orexin A and orexin B effect on $\left[\mathrm{Ca}^{2+}\right]_{\mathrm{i}}$ of serotonergic neurons in DRV measured with GCaMP6. $\mathbf{d}$ Original recordings (top) and heat maps of five individual neurons for each set of experiments (bottom). The recordings show the responses to the orexins and high $\mathrm{K}^{+}$saline. Dashed lines indicate the range where the responses were quantified. e Calcium responses upon $100 \mathrm{nM}$ orexin $\mathrm{A}$ and orexin $\mathrm{B}$. Data are shown as the percentage of the maximal response to high $\mathrm{K}^{+}$saline. Mean increases in $\left[\mathrm{Ca}^{2+}\right]_{\mathrm{i}}$ between experimental groups were compared, performing ANOVA with post hoc Tukey tests. Orexin A application: Ctrl vs Ox1R ${ }^{\Delta S E R T}, p=0.88$; Ctrl vs Ox2R ${ }^{\Delta S E R T}, p<0.0001 ;$ Ox1R ${ }^{\Delta S E R T}$ vs Ox2R ${ }^{\Delta S E R T}$, $p<0.0001$ (Ctrl, $n=159 ;$ Ox1R ${ }^{\Delta S E R T}, n=200 ;$ Ox2R $R^{\Delta S E R}, n=75$ ). Orexin B application: Ctrl vs Ox1R $\Delta$ SERT,$p=0.30 ;$ Ctrl vs Ox2R ${ }^{\Delta S E R T}, p<0.0001$; Ox1R ${ }^{\Delta S E R T}$ vS Ox2R ${ }^{\Delta S E R T}, p<0.0001$ (Ctrl, $n=75 ;$ Ox1R ${ }^{\Delta S E R T}, n=92 ; O x 2 R^{\Delta S E R T}, n=122$ ). In the box plots, the horizontal lines show the median of the data. Boxes indicate the 25th and 75th percentile. The whiskers were calculated according to the 'Tukey' method. ${ }^{*} p<0.05,{ }^{\star \star} p<0.01,{ }^{* \star *} p<0.001$, ${ }^{\star \star \star \star} p<0.0001 . n$ values are given in brackets. Source data are provided as a Source Data file.

significantly increased in mice exposed to HFD compared to $\mathrm{CD}$ feeding (Fig. 4a, b). Collectively, these data indicate an increased activation of orexin neurons in obese mice.

Then, we investigated the impact of Ox1R or Ox $2 \mathrm{R}$ inactivation in serotonergic system on energy homeostasis under both normal chow diet (NCD)-fed lean condition and HFD-induced obese condition. There were no differences in body weight (BW;
Fig. 4c, g), glucose tolerance under 16-h fasting condition (Fig. 4d, h) or insulin sensitivity under randomly fed condition (Fig. 4f, j) between control and Ox1R ${ }^{\triangle S E R T}$ mice. Two-way ANOVA revealed a significant decrease of glucose tolerance in obese $(F$ $(1,105)=7.86, p=0.0060)$ but not lean Ox1R $\mathrm{R}^{\Delta \mathrm{SERT}}$ mice, compared to control mice after a 6-h fasting period, though there was no significant change at individual time points by post 
CD

HFD

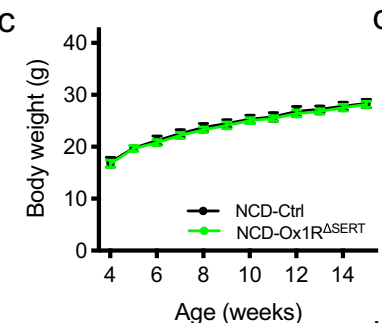

g
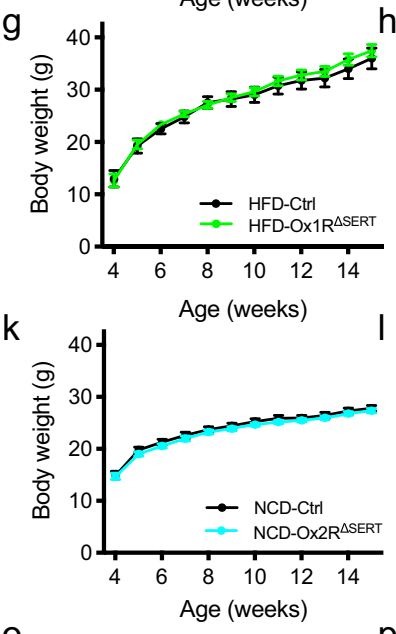

$\mathrm{O}$
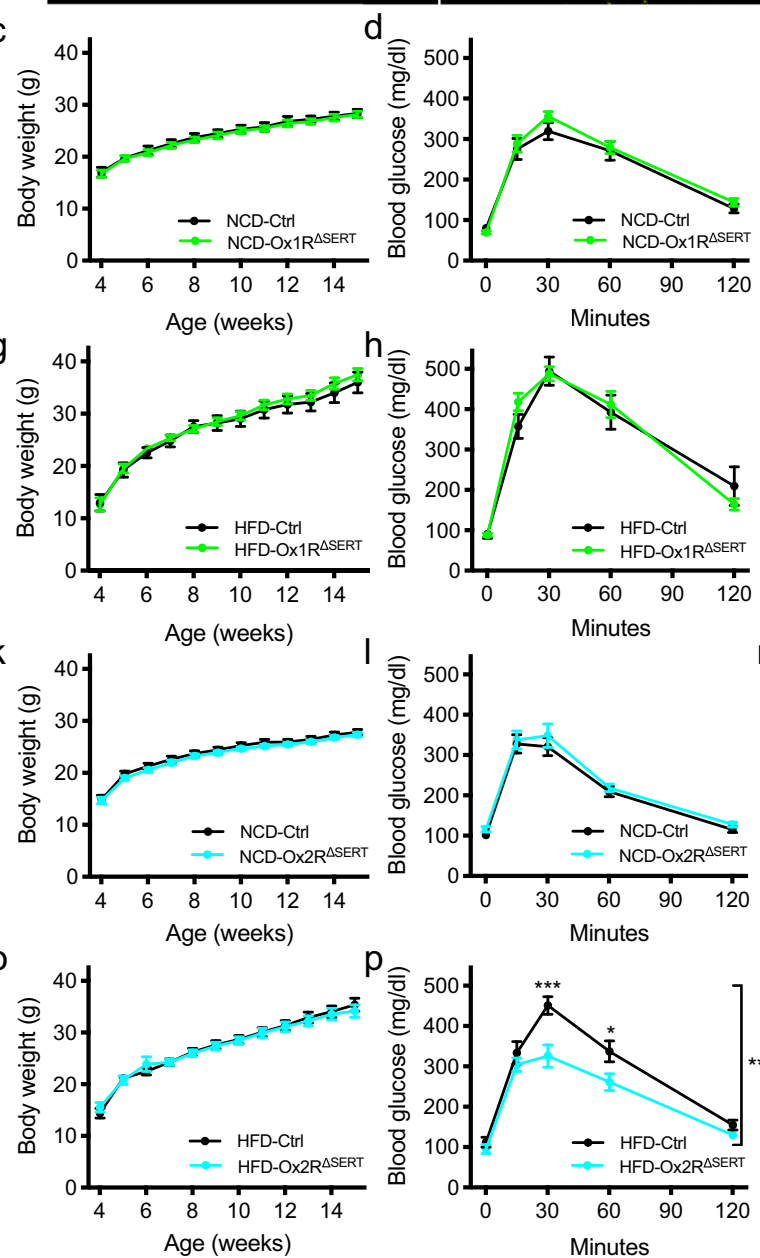

hoc test (Fig. 4e, i). Similarly, in lean Ox2 $\mathrm{R}^{\triangle \mathrm{SERT}}$ mice, BW, glucose tolerance, and insulin sensitivity remained unchanged (Fig. $4 \mathrm{k}-\mathrm{n}$ ). Interestingly, in obese $\mathrm{Ox} 2 \mathrm{R}^{\triangle \mathrm{SERT}}$ mice, glucose tolerance was significantly improved after a 16 -h fasting period (Fig. 4p), while BW and insulin sensitivity remained unchanged, compared to control mice (Fig. 4o, r). Two-way ANOVA revealed a significant improvement of glucose tolerance in obese
Merge

b
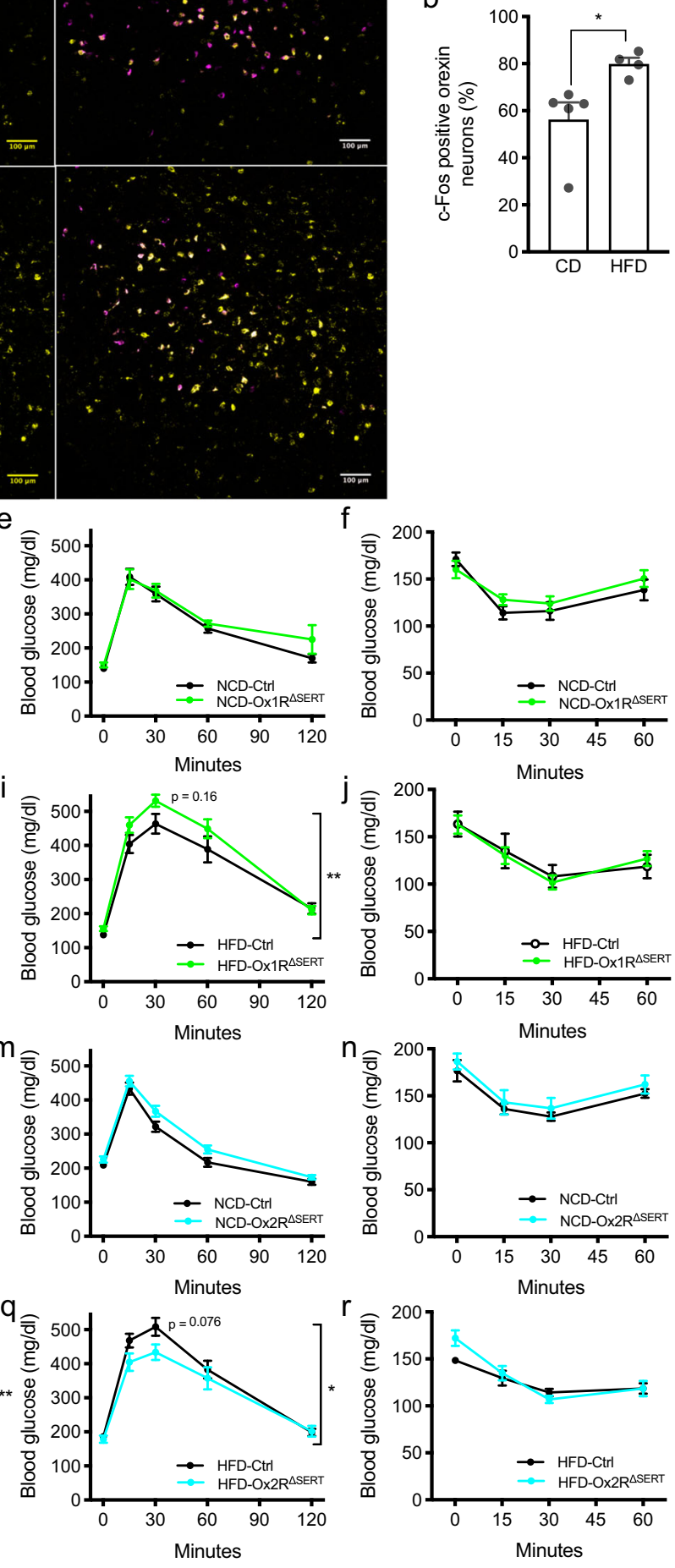

$\mathrm{Ox} 2 \mathrm{R}^{\triangle \mathrm{SERT}}$ mice, compared to control mice after a 6 -h fasting period, though there was no significant change at individual time points by post hoc test $((F(1,100)=6.08, p=0.015)$, Fig. $4 q)$.

Indirect calorimetry revealed unaltered locomotor activity and daily energy intake in Ox1R $\mathrm{R}^{\Delta \mathrm{SERT}}$ and $\mathrm{Ox} 2 \mathrm{R}^{\triangle \mathrm{SERT}}$ mice, compared to the respective control mice, under both lean and obese conditions (Supplementary Fig. 4). Collectively, these 
Fig. 4 Increased c-Fos activation in orexin neurons upon high-fat diet (HFD) feeding and improved glucose tolerance in Ox2R $\triangle$ SERT mice fed a HFD. a Representative images of RNAscope in situ hybridization in the lateral hypothalamus (LH) of a BL/6 mouse fed a control diet (CD) or HFD. $n=5$ (CD) and 4 (HFD). b Percentages of c-Fos positive neurons in orexin neurons. $n=5$ (CD) and 4 (HFD). $p=0.029$. $\mathbf{c}$, $\mathbf{g}$ Average body weight, glucose tolerance test under $\mathbf{d}, \mathbf{h}$ 16-h and $\mathbf{e}, \mathbf{i}$ 6-h fasting conditions, and $\mathbf{f}, \mathbf{j}$ insulin tolerance test of control (Ctrl) and Ox1R $\triangle$ SERT mice on normal chow diet (NCD) or HFD. NCDCtrl and NCD-Ox1R ${ }^{\triangle S E R T}, n=9 ;$ HFD-Ctrl, $n=8(\mathbf{g}, \mathbf{h}, \mathbf{j})$ or $11(\mathbf{i})$; HFD-Ox1R ${ }^{\triangle S E R T}, n=10(\mathbf{g}, \mathbf{h}, \mathbf{j})$ or $12(\mathbf{i})$. i $p=0.16$ at 30 min. $\mathbf{k}$, o Average body weight, glucose tolerance test under $\mathbf{I}, \mathbf{p}$ 16-h and $\mathbf{m}, \mathbf{q}$ 6-h fasting conditions, and $\mathbf{n}, \mathbf{r}$ insulin tolerance test of Ctrl and Ox2R $\triangle$ SERT mice on NCD or HFD. NCD-Ctrl,

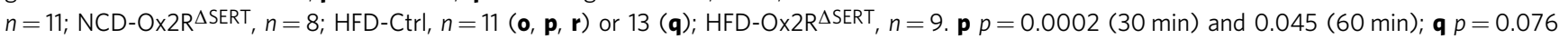
(30 min). Magenta, orexin; yellow, c-Fos. Scale bar: $100 \mu \mathrm{m}$. Data are represented as means \pm SEM. ${ }^{\star} p<0.05,{ }^{\star \star} p<0.01,{ }^{\star \star \star} p<0.001 ;$ as determined by unpaired two-tailed Student's $t$-test (b) or two-way ANOVA followed by Sidak's post hoc test (i, $\mathbf{p}, \mathbf{q})$. Two-way ANOVA revealed a significant main effect of genotype in (i) $(F(1,105)=7.86, p=0.0060), \mathbf{p}(F(1,90)=18.22, p<0.0001)$ and $\mathbf{q}(F(1,100)=6.08, p=0.015)$. Source data are provided as a Source Data file.
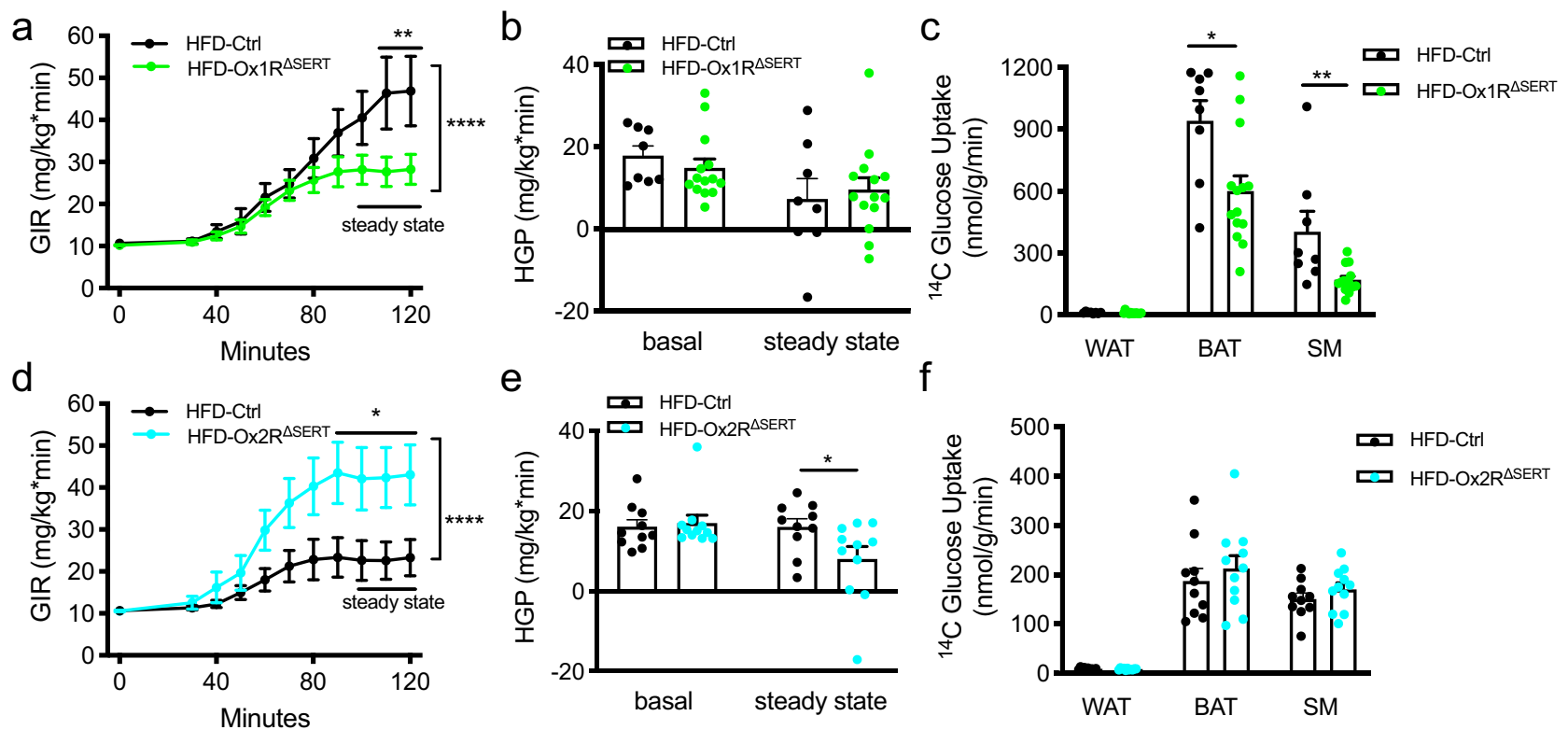

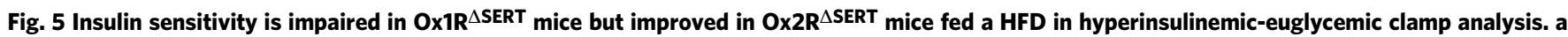
Clamp glucose infusion rates (GIR), b hepatic glucose production (HGP) in the basal state and during the steady state of clamp analysis, and $\mathbf{c}$ tissuespecific insulin-stimulated [1-14 C]-Deoxy-D-glucose uptake in white adipose tissue (WAT), brown adipose tissue (BAT), and skeletal muscle (SM) under steady-state conditions of control (Ctrl) and Ox1R ${ }^{\triangle S E R T}$ mice. HFD-Ctrl, $n=8 ;$ HFD-Ox1R ${ }^{\triangle S E R T}, n=14$. a $p=0.0025$ (110 min) and 0.0028 (120 min); c $p=0.011$ (BAT) and 0.0070 (SM). d Clamp GIR, e HGP in the basal state and during the steady state of clamp analysis, and $\mathbf{f}$ tissue-specific insulinstimulated [1-14C]-Deoxy-D-glucose uptake in WAT, BAT, and SM under steady-state conditions of control (Ctrl) and Ox2R ${ }^{\triangle S E R T}$ mice. HFD-Ctrl, $n=10$; HFD-Ox2R ${ }^{\Delta E R T}, n=11 . \mathbf{d} p=0.034(90 \mathrm{~min}), 0.047(100 \mathrm{~min}), 0.041(110 \mathrm{~min})$ and $0.042(120 \mathrm{~min}) ; \mathbf{e} p=0.048$. Data are represented as means $\pm \mathrm{SEM}$. ${ }^{\star} p<0.05,{ }^{\star \star} p<0.01$; as determined by two-way ANOVA followed by Sidak's post hoc test (a, d) or unpaired two-tailed Student's $t$-test (c, e). Two-way ANOVA revealed a significant main effect of genotype in $(\mathbf{a})(F(1,220)=18.30, p<0.0001)$ and $(\mathbf{d})(F(1,209)=35.39, p<0.0001)$. Source data are provided as a Source Data file.

results indicate that glucose metabolism is improved in obese mice upon selective inactivation of $\mathrm{Ox} 2 \mathrm{R}$ in serotonergic neurons.

Insulin-stimulated HGP suppression and tissue glucose uptake in obese $O x 1 R^{\Delta S E R T}$ and $O x 2 R^{\Delta S E R T}$ mice. To further specifically address the regulation of glucose metabolism in HFD-induced obese Ox1R $\mathrm{R}^{\triangle \mathrm{SERT}}$ and Ox $2 \mathrm{R}^{\Delta \mathrm{SERT}}$ mice, we performed hyperinsulinemiceuglycemic clamp studies. The glucose infusion rate (GIR) required to maintain euglycemia during steady-state conditions was significantly reduced in Ox $1 \mathrm{R}^{\triangle \mathrm{SERT}}$ mice, compared to their littermate control mice (Fig. 5a, Supplementary Fig. 5a). Hepatic glucose production (HGP) was not significantly different between control and Ox1R $\mathrm{R}^{\triangle \mathrm{SERT}}$ mice under basal clamp conditions or in response to insulin (Fig. 5b). Interestingly, the rate of plasma glucose disappearance (Rd) was significantly decreased in Ox1R $\mathrm{R}^{\triangle \mathrm{SERT}}$ mice at a steady state while the levels under basal clamp conditions were not significantly different (Supplementary Fig. 5b). Determination of tissue-specific glucose uptake revealed impaired glucose uptake into
BAT and skeletal muscle (SM) of obese Ox1R $\triangle$ SERT mice, while glucose uptake into white adipose tissue (WAT) remained unchanged (Fig. 5c). In contrast, GIR was significantly increased during steady-state conditions in $\mathrm{Ox} 2 \mathrm{R}^{\Delta \mathrm{SERT}}$ mice compared to their littermate control mice (Fig. 5d, Supplementary Fig. 5d). Ox2R ${ }^{\Delta S E R T}$ mice exhibited similar HGP levels under basal clamp conditions but significantly lower HGP at steady state, compared to control mice, indicating that the suppression of HGP was more efficient in response to insulin in obese $\mathrm{Ox} 2 \mathrm{R}^{\triangle \mathrm{SERT}}$ mice (Fig. 5e). There was no significant difference of $\mathrm{Rd}$ or tissue-specific glucose uptake between control and Ox2R $\mathrm{R}^{\triangle \mathrm{SERT}}$ mice (Fig. 5f, Supplementary Fig. 5e). The insulin infusion was confirmed by detecting human insulin levels in serum at baseline and at the end of hyperinsulinemic-euglycemic clamp studies (Supplementary Fig 5c, f).

Altered liver and BAT in obese $O \times 1 R^{\Delta S E R T}$ and $O x 2 R^{\Delta S E R T}$ mice in hyperinsulinemic-euglycemic clamp studies. To investigate the mechanisms underlying the effect of serotonergic- 


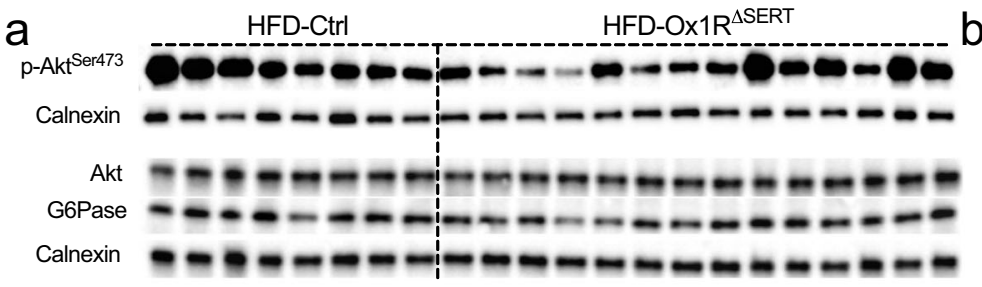

C
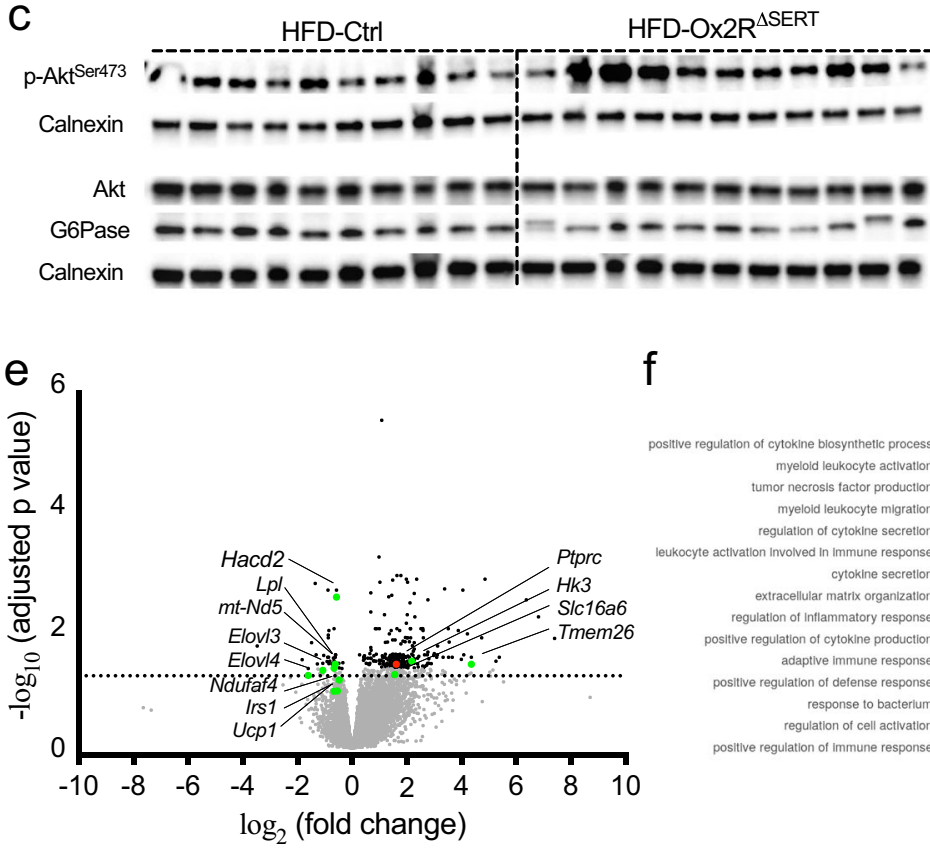

f
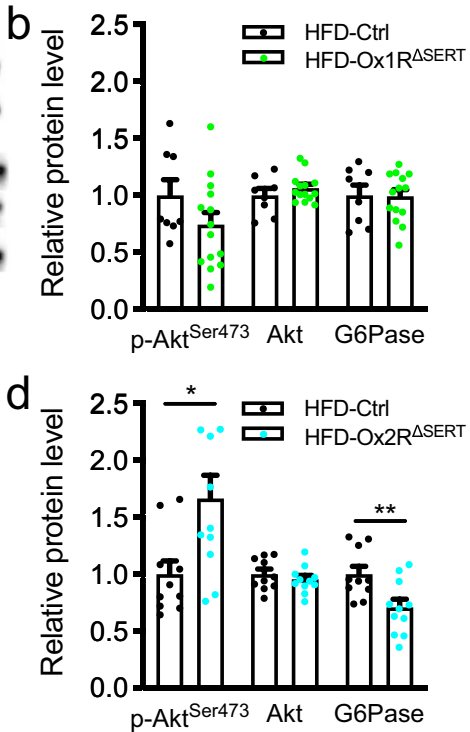

Top 15 sig. terms, ordered by overlap

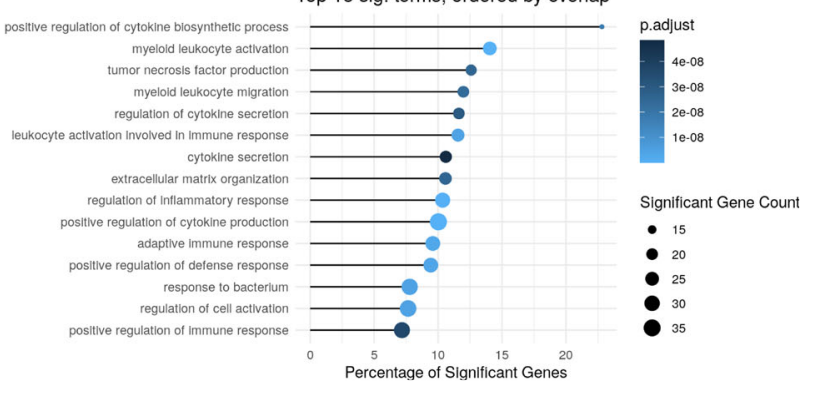

Fig. 6 Insulin signaling in liver and BAT in obese $\mathbf{O} \mathbf{X R}^{\mathbf{\Delta S E R T}}$ and $\mathbf{O} \mathbf{X R R}^{\mathbf{\Delta S E R T}}$ mice. a, $\mathbf{b}$ Western blot images and quantification of p-Akt ${ }^{\mathrm{Ser}} 473$, Akt, and G6Pase protein in the liver of control and Ox1R ${ }^{S E R T}$ mice. HFD-Ctrl, $n=8 ;$ HFD-Ox1R $\triangle$ SERT, $n=14$. $\mathbf{c}$, d Western blot images and quantification of p-AktSer473, Akt, and G6Pase protein in the liver of control and Ox2R ${ }^{\Delta S E R T}$ mice. HFD-Ctrl, $n=10$; HFD-Ox2R $\Delta$ SERT, $n=11 . p=0.013$ ( $p-A k t S e r 473$ ) and 0.0085 (G6Pase). Data are represented as means \pm SEM. ${ }^{\star} p<0.05,{ }^{\star \star} p<0.01$; as determined by unpaired two-tailed Student's $t$-test. e Volcano plot of differential expression analysis of RNA sequencing of BAT in OxIR ${ }^{\triangle S E R T}$ mice, compared to control mice. Some genes of interest are annotated. The differential gene expression test was done using negative binomial generalized linear models implemented in DESeq2 1.26.0. P-values are false discovery rates adjusted using the Benjamini-Hochberg procedure. $\mathbf{f}$ Top 15 differentially regulated gene ontology (GO) terms of class biological process in BAT of OxIR $\triangle \mathrm{SERT}$ mice, compared to control mice. Significance is mapped to color, the dot size represents the number of significant genes in the GO term and the $x$-axis maps the percentage of significant genes to the overall gene GO term size. Gene-ontology term analysis of the 265 differentially expressed genes was carried out using the clusterProfiler R package, which utilizes an over-representation analysis calculating $p$-values by hypergeomtric distributions. $P$-values are FDR-adjusted. $n=4$. Source data are provided as a Source Data file.

specific inactivation of $\mathrm{Ox} 1 \mathrm{R}$ or $\mathrm{Ox} 2 \mathrm{R}$ in hyperinsulinemiceuglycemic clamp studies, we further analyzed gene and protein expression in the liver and BAT dissected from these animals under clamp steady-state conditions.

In the liver, $\mathrm{p}-\mathrm{Akt} \mathrm{Ser}^{\mathrm{S} 73}$ protein, the major downstream effector of the insulin signaling pathway, was significantly increased in $\mathrm{O} 22 \mathrm{R}^{\triangle \mathrm{SERT}}$ mice but unchanged in Ox1 $\mathrm{R}^{\triangle \mathrm{SERT}}$ mice, compared to control mice, while the total Akt protein levels remained unchanged (Fig. 6a-d). Glucose-6-phosphatase (G6Pase) protein, which is essential for gluconeogenesis, was significantly decreased in $\mathrm{Ox} 2 \mathrm{R}^{\triangle \mathrm{SERT}}$ mice but unchanged in $\mathrm{Ox} 1 \mathrm{R}^{\triangle \mathrm{SERT}}$ mice, compared to control mice (Fig. 6a-d).

To investigate the mechanisms of glucose uptake reduction in BAT of obese Ox1R $\mathrm{R}^{\triangle \mathrm{SERT}}$ mice compared to control mice, we compared the gene expression profiles of BAT dissected under clamp steady-state conditions from $\mathrm{Ox} 1 \mathrm{R}^{\triangle \mathrm{SERT}}$ and control mice by total mRNA sequencing. This analysis revealed 265 genes significantly regulated in Ox1 $\mathrm{R}^{\Delta \mathrm{SERT}}$ mice compared to control mice. The fatty acid elongase genes Elovl3 and Elovl4, the lipoprotein lipase gene $L p l$, the very-long-chain (3R)-3-hydroxyacyl-CoA dehydratase 2 gene $H a c d 2$, the mitochondrial genes $m t-N d 5$ and Ndufaf4 involved in Complex I and oxidative phosphorylation, the uncoupling protein 1 gene Ucp 1 and the insulin receptor substrate 1 gene Irs1 were decreased in Ox1R $\triangle$ SERT mice compared to control mice, though some of them were statistically non-significant (Fig. 6e). In addition, the beige adipocytes marker transmembrane marker 26 gene Tmem 26 and genes regulating glucose metabolism, including the solute carrier family 16 member 6 gene Slc16a6 and hexokinase 3 gene $H k 3$, were increased in expression (Fig. 6e). Of note, the leukocyte antigen CD45 gene Ptprc was significantly increased and the ontology enrichment analysis revealed robust increase of immune response and inflammation in Ox $1 \mathrm{R}^{\triangle \mathrm{SERT}}$ mice compared to control mice (Fig. 6e, f). The top 15 enriched gene ontology (GO) terms include positive regulation of cytokine production, myeloid leukocyte activation, regulation of inflammatory response, etc. (Fig. 6f). Among the significantly regulated genes, numerous relate to immune system, such as Cd5l, Fcgr1, 
Trem2, CD80, Tnfsf8, Tnfaip6, Cxcl3, Ccr1 (Source Data of Fig. 6e).

Impact on BAT in obese $O x 1 R^{\Delta S E R T}$ and $O x 2 R^{\Delta S E R T}$ mice. Next, we assessed BAT weight and morphology in HFD-induced obese Ox1R ${ }^{\triangle S E R T}$ mice. The percentage of BAT mass weight to $\mathrm{BW}$ was significantly increased in Ox1R ${ }^{\triangle \mathrm{SERT}}$ mice compared to control mice (Supplementary Fig. 6a). Histomorphological analysis revealed large lipid droplets in BAT of Ox1R ${ }^{\triangle S E R T}$ mice (Fig. 7a) and transmission electron microscopy (TEM)-analyses revealed that the aspect ratio (the ratio of long axis to the short axis) of mitochondria was significantly decreased in Ox $1 \mathrm{R}^{\triangle \mathrm{SERT}}$ mice, while the average mitochondrial area remained unchanged (Fig. 7b-d). Analysis of relative mitochondrial DNA content revealed no changes between control and Ox1R ${ }^{\Delta S E R T}$ mice (Fig. 7e). Gene expression analyses demonstrated reduced expression of fatty acid oxidation-associated enzyme Acox3; Vegfa, which modulates mitochondrial function; Ppargcla, which is important for mitochondrial biogenesis; Cycs, which functions in oxidative phosphorylation (OXPHOS); and Dnm1l, which mediates mitochondrial fission process in Ox1R ${ }^{\Delta S E R T}$ mice compared to their littermate controls (Fig. 7f, Supplementary Table 1). Mfnl gene, which mediates mitochondrial fusion showed a tendency to be decreased in Ox1R $\mathrm{R}^{\triangle \mathrm{SERT}}$ mice, while Mfn2, Fis1, and Mff genes mediating mitochondrial fusion or fission were not significantly changed (Fig. 7f, Supplementary Table 1). Protein expression analysis supported the findings of impaired mitochondrial dynamics, oxidative phosphorylation, and thermogenesis. In Ox $1 \mathrm{R}^{\triangle \mathrm{SERT}}$ mice, the protein expression of UCP-1, OXPHOS complex I CI-NDUFB8, complex IV CIVMTCO1, mitofusin 1 (MFN1), and fission 1 (FIS1) were significantly reduced and complex II CII-SDHB also showed a tendency to be decreased (Fig. $7 \mathrm{~g}-\mathrm{l}$ ). The mitochondrial protein import receptor TOM20, complex III CIII-UQCRC2, complex V CV-ATP5A, fusion proteins optic atrophy type 1 (OPA1) and mitofusin 2 (MFN2), and fission proteins dynamin-related protein 1 (DRP1) and mitochondrial fission factor (MFF) remained unchanged (Fig. $7 \mathrm{~g}-1$ ).

In contrast to obese $\mathrm{Ox} 1 \mathrm{R}^{\triangle \mathrm{SERT}}$ mice, obese $\mathrm{Ox} 2 \mathrm{R}^{\triangle \mathrm{SERT}}$ mice showed unaltered BAT mass weight, morphology as detected with haematoxylin and eosin (H\&E) staining, gene expression levels of Acox3, Vegfa, Ppargc1a, Cycs, Mfn1, Mfn2, Dnm1l, Fis1 and Mff, and protein expression levels of UCP1, compared to control mice (Fig. $7 \mathrm{~m}-$ p, Supplementary Fig. 6b).

Glucose metabolism upon optogenetic stimulation of orexin neurons in LH or orexinergic fibers in RPa. Next, we investigated the impact of activation of the orexin system on glucose metabolism by insulin tolerance test (ITT) and glucose tolerance test (GTT), using an optogenetic approach. Orexin-Cre mice were created and the expression pattern of Cre was analyzed by crossing Orexin-Cre transgenic mice and channelrhodopsin-2 (ChR2)-tdTomato fl/fl mice. tdTomato was specifically expressed in orexin A-positive cells in LH (Supplementary Fig. 7e, k). In addition, we could detect a small cluster of tdTomato singlelabeled cells below the lateral ventricle and around the 3rd ventricle and several scattered cells in other brain regions (Supplementary Fig. 7a-j). We injected an adeno-associated virus (pAAV-EF1a-double floxed-hChR2-EYFP) into the LH of Orexin-Cre mice to obtain expression of ChR2 and enhanced yellow fluorescent protein (EYFP) induced by Cre-loxP recombination in orexin neurons (Orexin ChR2-EYFP). Control mice were injected with pAAV-Ef1a-DIO-EYFP (Orexin ${ }^{\mathrm{EYFP}}$ ). The efficiency and specificity of ChR2-EYFP and EYFP expression were evaluated with immunostaining of orexin and EYFP in LH. The
EYFP signal could be localized in orexin-positive cells exclusively (Fig. 8a). $70.95 \%$ and $76.23 \%$ of orexin neurons were EYFP positive in Orexin ${ }^{\text {EYFP }}$ and Orexin ChR2-EYFP mice, respectively (Fig. 8b).

The optical fiber was implanted above LH in AAV-injected mice to allow optogenetic activation of orexin neurons (Fig. 8c, Supplementary Fig. 8a). Blue light $(473 \mathrm{~nm})$ laser illumination $(20 \mathrm{~mW}, 20 \mathrm{~Hz}, 10 \mathrm{~ms}$ pulse, $10 \mathrm{~s}$ on in every $45 \mathrm{~s})$, which started 30 min before glucose or insulin injection and lasted until the end of ITT and GTT experiments under random-fed or 6-h fasting conditions respectively, significantly impaired glucose tolerance $15 \mathrm{~min}$ after glucose injection (Fig. 8d) and insulin sensitivity revealed by two-way ANOVA $(F(1,80)=7.00, p=0.0098$; Fig. 8e). Accordingly, c-Fos expression was significantly increased in orexin neurons of OrexinChR2-EYFP mice compared to OrexinEYFP mice (fasted for $6 \mathrm{~h}$ ) after $1 \mathrm{~h}$ of laser illumination (Fig. 8f, g). c-Fos positive orexin neurons were detectable throughout the $\mathrm{LH}$ and we did not observe topographic segregation. DR- and $\mathrm{RPa}-$ projecting cells were distinct and intermingled in $\mathrm{LH}$, as revealed by retrograde tracing with red and green retrobeads injected to DR and RPa respectively (Fig. $8 \mathrm{~h}-\mathrm{j}$ ).

Innervation of orexinergic nerve fibers was analyzed by staining of serotonin, orexin, and EYFP in RN of AAV-injected mice. There were abundant orexin- and EYFP-positive nerve fibers which co-localized with serotonin neurons in all $\mathrm{RN}$ regions, including DRD, DRV, MRD, MRV, and RPa, of control (Fig. 9a) and Orexin ChR2-EYFP mice (Fig. 9b). This indicates that orexin nerve fibers innervate $\mathrm{RN}$ and the ChR2 protein travels successfully to these nerve endings. Further, we implanted the optical fiber above RPa in AAV-injected mice to selectively activate orexinergic fibers in this projection field (Fig. 9c, Supplementary Fig. 8b). Laser illumination $(10 \mathrm{~mW}, 20 \mathrm{~Hz}$, $10 \mathrm{~ms}$ pulse, $10 \mathrm{~s}$ on in every $45 \mathrm{~s}$ ) in $\mathrm{RPa}$, which started $30 \mathrm{~min}$ before glucose or insulin injection and lasted until the end of experiments, significantly improved glucose tolerance $15 \mathrm{~min}$ after glucose injection in GTT under 6-h fasting conditions (Fig. 9d). Insulin sensitivity remained unchanged upon laser illumination in RPa, as assessed by ITT (Fig. 9e). c-Fos positive serotonergic neurons in $\mathrm{RPa}$ were significantly increased in OrexinChR2-EYFP mice compared to Orexin ${ }^{\text {EYFP }}$ mice (fasted for $6 \mathrm{~h}$ ) after $1 \mathrm{~h}$ of laser illumination (Fig. 9f, g), without evidence for significant back-propagation to orexin neurons in the LH (Supplementary Fig. 9e, f).

Laser illumination in $\mathrm{LH}$ or $\mathrm{RPa}$ failed to affect glucose metabolism in control mice, as measured by ITT and GTT (Supplementary Fig. 9a-d).

\section{Discussion}

$\mathrm{DR}$ and MR in the midbrain and pons contain the majority of serotonergic neurons, which mainly project to the forebrain, while serotonergic neurons in caudal $\mathrm{RN}$, such as $\mathrm{RPa}$, mainly project to the brain stem and periphery ${ }^{35}$. We find that, among the different $\mathrm{RN}$ regions, Ox1R is dominantly expressed in DRD while Ox $2 R$ is dominantly expressed in DRV, and only Ox $1 R$ could be clearly detected in serotonergic neurons in MRV and $\mathrm{RPa}$. In line with this, a previously published RNA-seq data study shows that $\mathrm{Ox} 2 \mathrm{R}$ is dominantly expressed in serotonergic neurons in DR, less expressed in the relatively dorsal and median regions of $\mathrm{MR}$, and rarely expressed in ventral MR or caudal $\mathrm{RN}^{20}$. In addition, a recently published scRNA-seq data study shows that $\mathrm{Ox} 1 \mathrm{R}$ is expressed at different levels among 5 subtypes of serotonergic neurons in $\mathrm{DR}^{30}$.

Both Ox1R and Ox2R mediate an excitatory direct response upon orexin stimulation in serotonergic neurons, as found in our study and previous studies by others ${ }^{33,36,37}$. Consistent with the 

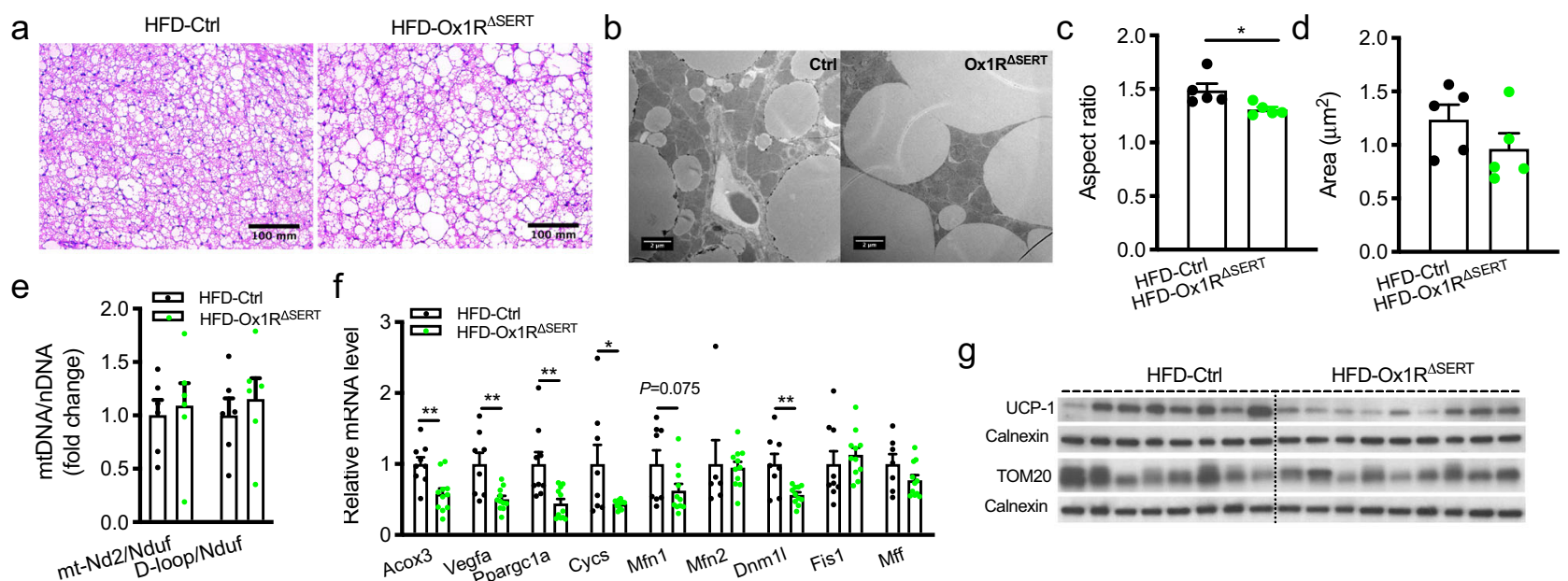

h

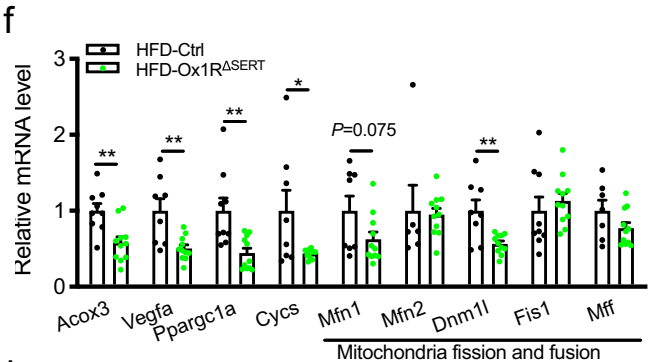

g

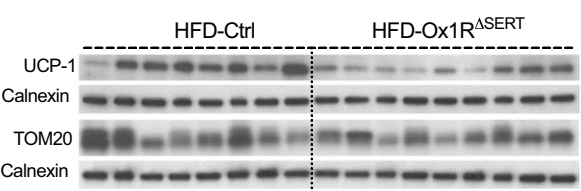

j
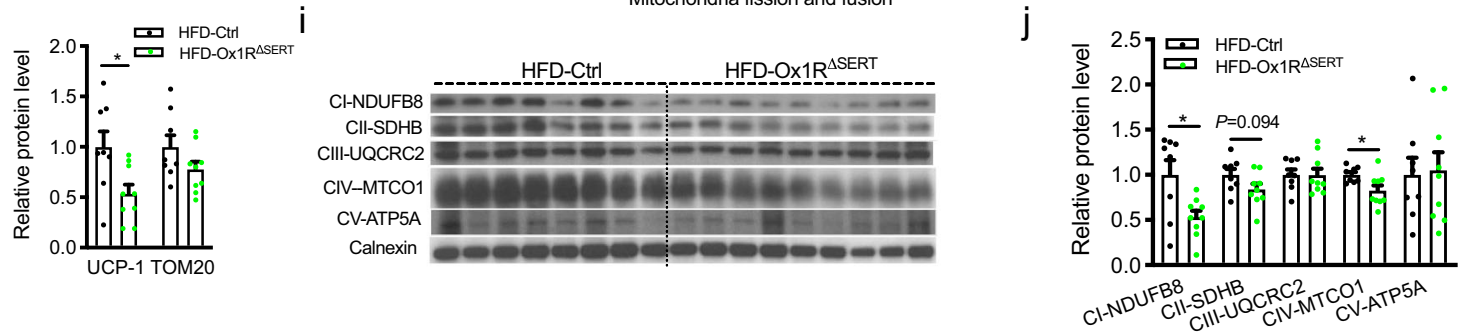

CI-ND CIIII-U CIN-M CV-T

k

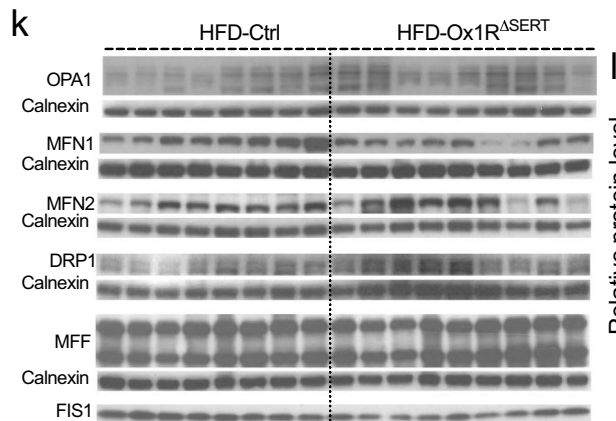

$\mathrm{n}$

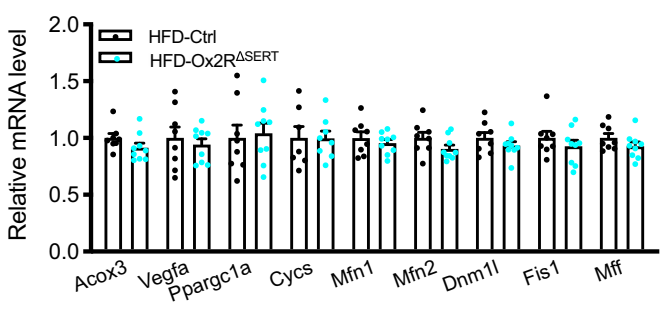

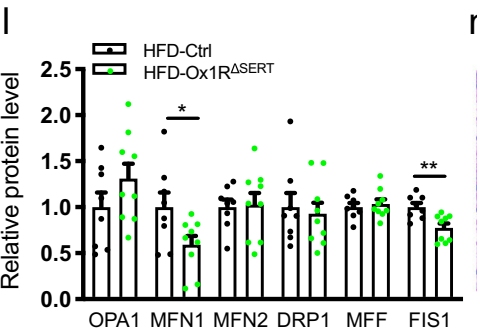

m
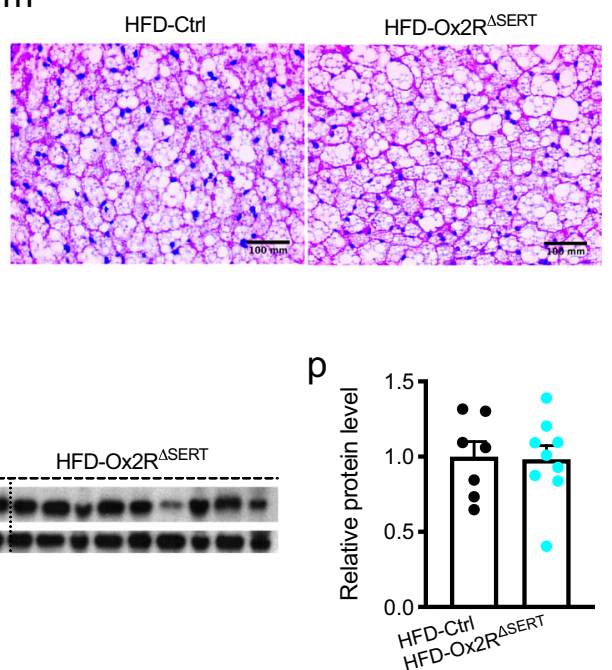

Fig. 7 Increased fat and impaired mitochondrial function in brown adipose tissue (BAT) of Ox1R ${ }^{\Delta S E R T}$ mice while BAT morphology and mitochondrial function are unaltered in $\mathbf{0 x} \mathbf{2} \mathbf{R}^{\triangle \mathrm{SERT}}$ mice fed a high-fat diet (HFD). a H\&E staining of BAT of control or Ox1R ${ }^{\triangle S E R T}$ mice. HFD-Ctrl, $n=8$; HFDOx1R $\triangle$ SERT,$n=10$. b Representative electronic microscope (EM) images of BAT of control and Ox1R $\triangle S E R T$ mice, and quantification of $\mathbf{c}$ mitochondrial area and $\mathbf{d}$ mitochondrial aspect ratio. $n=5 . p=0.033$. e Relative mitochondrial DNA content of control and OxiR $\triangle S E R T$ mice. $n=6$. $\mathbf{f}$ Gene expression levels in BAT of control and Ox1R ${ }^{\Delta S E R T}$ mice. Control: $n=6$ (Mfn2), 7 (Mff), 8 (Vegfa, Cycs, Mfn1, Dnm11) and 9 (Acox3, Ppargc1a, Fis1); Ox1R ${ }^{\Delta S E R T}, n=11$. $p=0.0026$ (Acox3), 0.0031 (Vegfa), 0.0038 (Ppargc1a), 0.024 (Cycs), 0.075 (Mfn1) and 0.0035 (Dnm11). $\mathbf{g}$, h Western blot images and quantification of UCP-1 and TOM20 protein, $\mathbf{i}, \mathbf{j}$ OXPHOS protein, and $\mathbf{k}$, I mitochondrial fusion and fission protein in BAT of control and Ox1R $\triangle$ SERT mice. UCP1 and FIS1 were from the same western blot gel and thus shared the loading control. HFD-Ctrl, $n=8$; HFD-Ox1R ${ }^{\Delta S E R T}, n=9 . p=0.020$ (UCP-1), 0.015 (CINDUFB8), 0.094 (CII-SDHB), 0.021 (CIV-MTCO1), 0.038 (MFN1) and 0.0039 (FIS1). $\mathbf{m}$ H\&E staining of BAT of control and Ox2R ${ }^{\triangle S E R T}$ mice. HFD-Ctrl, $n=11 ; \mathrm{HFD}-\mathrm{Ox} 2 \mathrm{R}^{\triangle \mathrm{SERT}}, n=9 . \mathbf{n}$ Gene expression levels in BAT of control and Ox2R $\triangle$ SERT mice. HFD-Ctrl, $n=8$ except for Cycs ( $\left.n=7\right) ; \mathrm{HFD}-\mathrm{Ox} 2 \mathrm{R} \Delta \mathrm{SERT}$, $n=9$ except for Cycs $(n=8)$. o, $\mathbf{p}$ Western blot images and quantification of UCP-1 protein in BAT of control and Ox2R ${ }^{\triangle S E R T}$ mice. HFD-Ctrl, $n=7$; HFDOx2R 2 SERT,$n=9$. Scale bar: $100 \mathrm{~mm}$ in $(\mathbf{a}, \mathbf{m})$ and $2 \mu \mathrm{m}(\mathbf{b})$. Data are represented as means \pm SEM. ${ }^{*} p<0.05,{ }^{\star \star} p<0.01$; as determined by unpaired twotailed Student's $t$-test. Source data are provided as a Source Data file. 


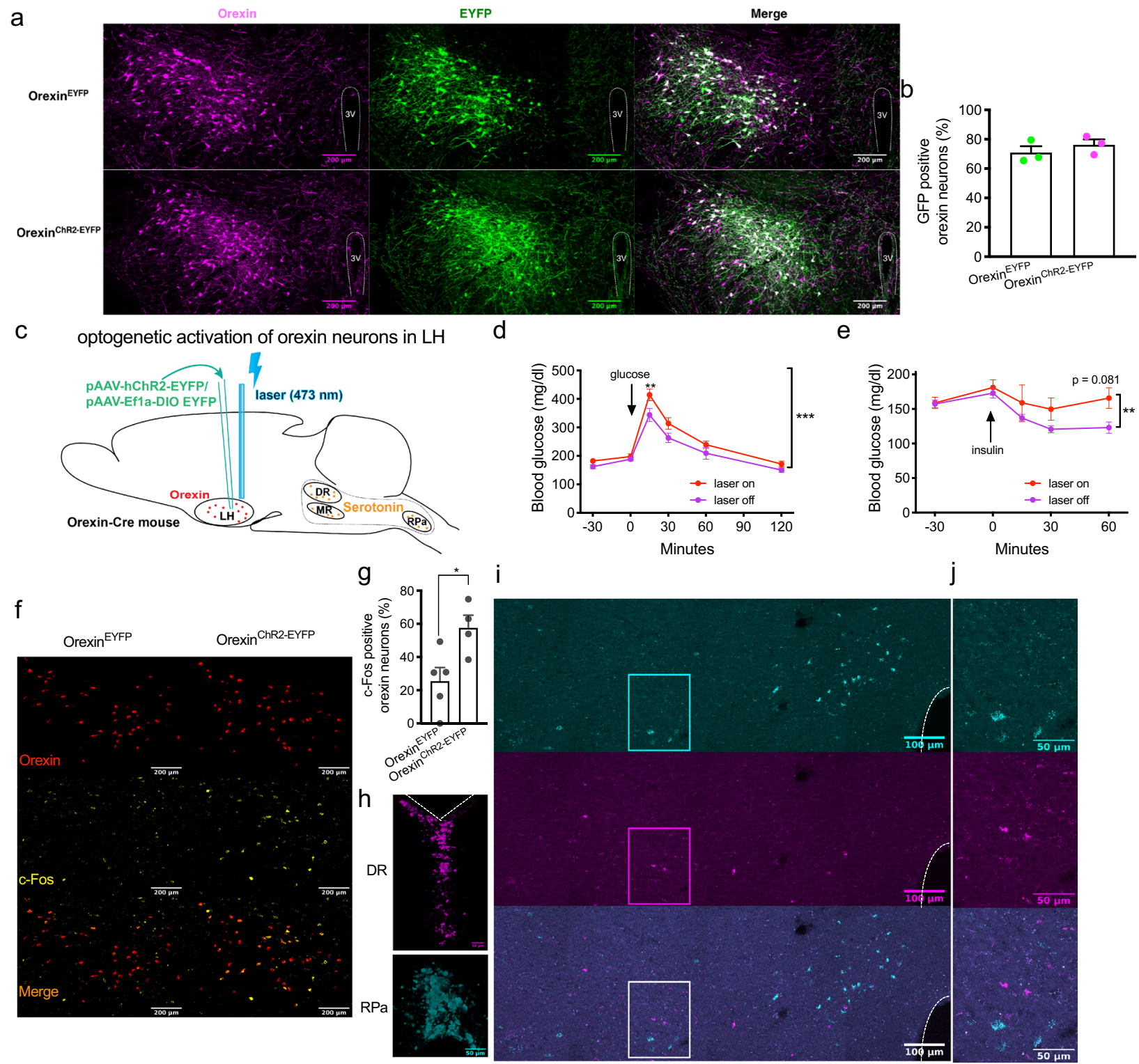

Fig. 8 Optogenetic stimulation of orexin neurons impairs glucose tolerance. a Representative images of immunostaining of orexin and EYFP in the lateral hypothalamus (LH) of Orexin-Cre mice injected with Cre-dependent adeno-associated virus pAAV-EYFP (OrexinEYFP) or pAAV-ChR2-EYFP (OrexinChR2-EYFP). $n=3$. $\mathbf{b}$ Quantification of percentages of GFP positive neurons in orexin neurons of mice injected with AAV. $n=3$. Magenta, orexin; green, EYFP. c Schematic drawing of the strategy of optogenetic stimulating of orexin neurons. $\mathbf{d}$ Glucose tolerance test and $\mathbf{e}$ insulin tolerance test of Orexin ChR2-EYFP mice with (laser on) or without (laser off) laser illumination in LH. $\mathbf{d} n=10, p=0.0056$ (15 min); e $n=9, p=0.081$ (60 min). f Representative images of RNAscope in situ hybridizations of c-Fos and orexin in $\mathrm{LH}$ and $\mathbf{g}$ the quantification of percentages of c-Fos positive neurons in orexin neurons after laser illumination. $n=5$ or 4 . $p=0.027$. Red, orexin; yellow, c-Fos. $\mathbf{h}$ Representative images of retrobeads injected in dorsal raphe nucleus (red beads) and raphe pallidus (green beads). $\mathbf{i}$ Representative images of retrobeads traveled to $\mathrm{LH}$, in which the squares-indicated regions were amplified in (j). $n=5$. Magenta, red beads; cyan, green beads. Scale bar: $200 \mu \mathrm{m}(\mathbf{a}, \mathbf{f})$, $100 \mu \mathrm{m}(\mathbf{i})$ or $50 \mu \mathrm{m}(\mathbf{h}, \mathbf{j})$. Data are represented as means \pm SEM. ${ }^{\star} p<0.05,{ }^{\star \star} p<0.01,{ }^{\star \star \star} p<0.001$; as determined by unpaired two-tailed Student's t-test ( $\mathbf{g}$ ) or two-way ANOVA followed by Sidak's post hoc test $(\mathbf{d}, \mathbf{e})$. Two-way ANOVA revealed a significant main effect of genotype in $(\mathbf{d})(F(1,108)=15.75, p=0.0001)$, and $(\mathbf{e})(F(1,80)=7.00, p=0.0098)$. Source data are provided as a Source Data file.

differential expression pattern of orexin receptors in $\mathrm{DR}, \mathrm{Ca}^{2+}$ imaging reveals that, in DRV, the unselective endogenous agonist orexin A-induced excitation of serotonergic neurons is mainly mediated by Ox2R. Both electrophysiological and GCaMP experiments find that the excitation of serotonergic neurons by orexin $\mathrm{B}$, which is more selective for Ox2R activation ${ }^{38}$, is attenuated by $\mathrm{Ox} 2 \mathrm{R}$ deletion in serotonergic neurons but not by Ox1R deletion. Together with our RNAscope findings for Ox1R or Ox2R in serotonergic neurons of Ox1R ${ }^{\triangle S E R T}$ or Ox1R ${ }^{\triangle S E R T}$ mice, respectively, this suggests that our Cre-loxP recombination-mediated conditional knockout model is specific and efficient.

Deletion of either orexin receptor in serotonergic cells is insufficient to alter glucose metabolism and/or energy homeostasis in lean mice. However, it has opposing effects under conditions of HFD-induced obesity when the orexin system is more activated. This indicates that orexin signaling in serotonergic neurons is more crucial for maintaining energy homeostasis under obese conditions, compared to lean conditions. Consistent with this hypothesis, we found orexin neurons 
a

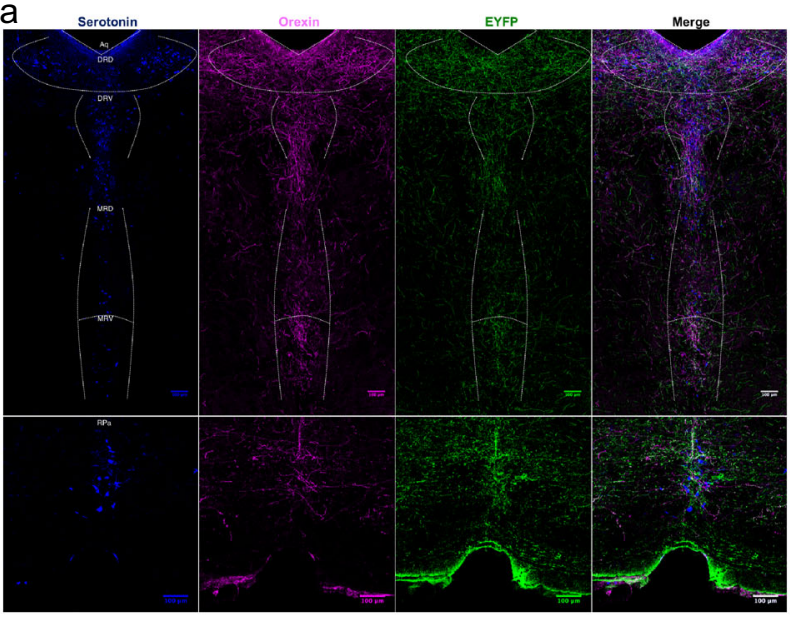

C

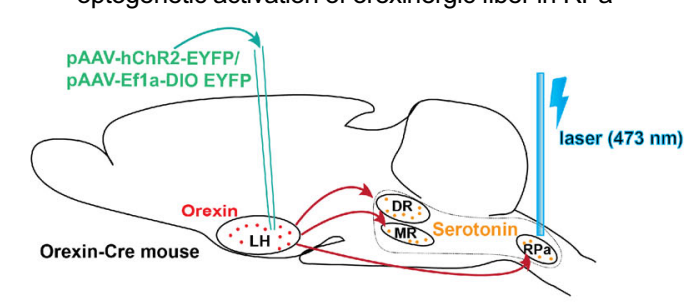

$f_{\text {Orexin }^{\text {EYFP }}}$ b

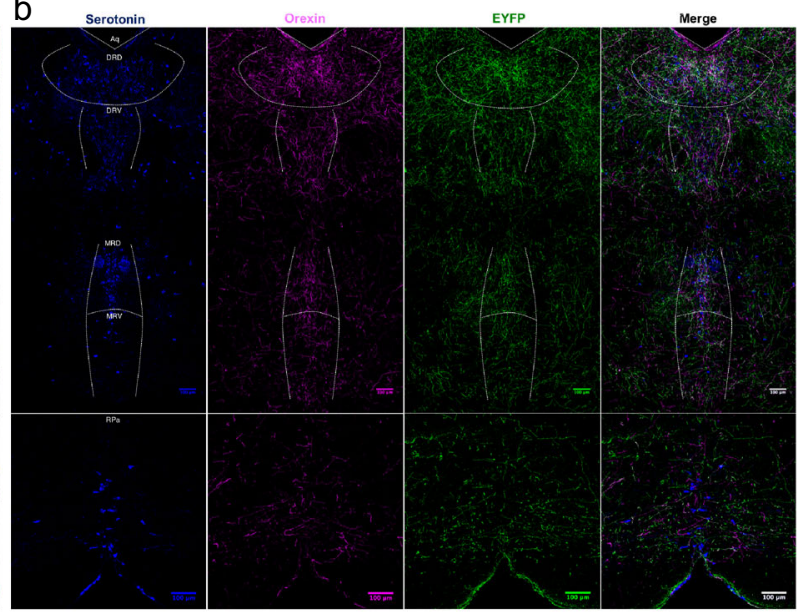

d

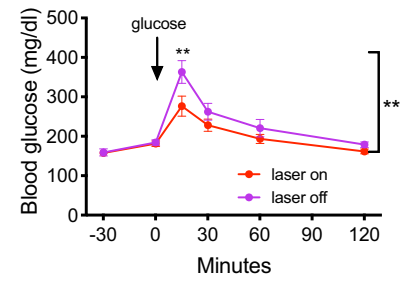

Orexin $^{\text {ChR2-EYFP }}$ e

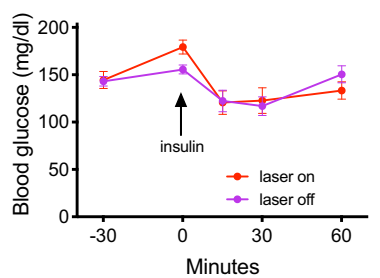

g
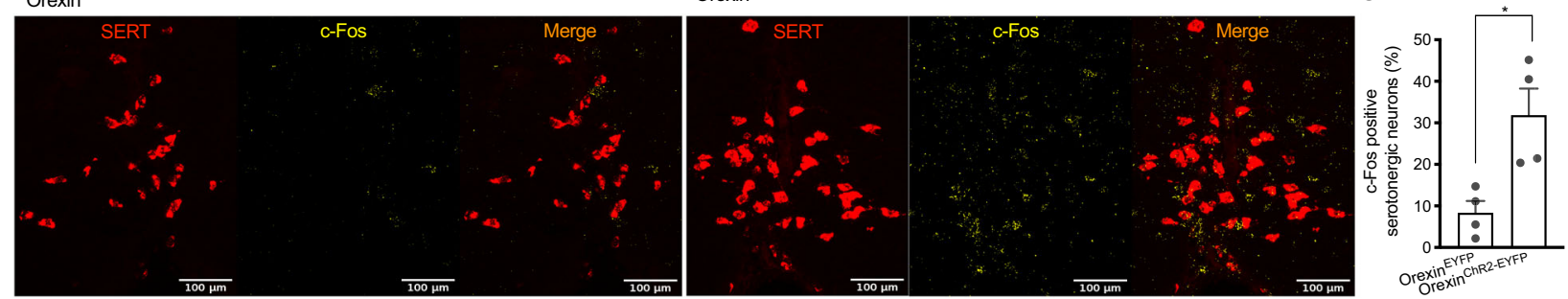

Fig. 9 Optogenetic stimulation of orexinergic fibers in raphe pallidus ( $R$ Pa) improves glucose tolerance. a Representative images of immunostaining of

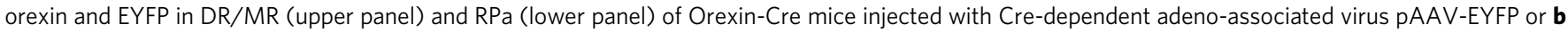
pAAV-ChR2-EYFP virus (Orexin ChR2-EYFP). $n=3$. Blue, serotonin; magenta, orexin; green, EYFP. c Schematic drawing of the strategy of optogenetic stimulation of orexinergic fibers in RPa. d Glucose tolerance test and e insulin tolerance test of OrexinChR2-EYFP mice with (laser on) or without (laser off) laser illumination in RPa. $n=8$. d $p=0.0015$ (15 min). $\mathbf{f}$ Representative images of RNAscope in situ hybridization of c-Fos and serotonin transporter (SERT) in raphe pallidus and $\mathbf{g}$ the quantification of percentages of $\mathrm{c}$-Fos positive neurons in serotonergic neurons after laser illumination. $n=4$. $p=0.015$. Red, SERT; yellow, c-Fos. Scale bar: $100 \mu \mathrm{m}$. Data are represented as means \pm SEM. ${ }^{\star} p<0.05,{ }^{\star \star} p<0.01$; as determined by unpaired two-tailed Student's $t$-test (g) or two-way ANOVA followed by Sidak's post hoc test (d). Two-way ANOVA revealed a significant main effect of genotype in (d) ( $F$ ( 1,84$)=9.34$, $p=0.0030$ ). Source data are provided as a Source Data file.

were more activated in HFD-fed mice compared to CD-fed mice under fasting conditions. Previous reports also show that orexin receptors regulate energy metabolism differently in lean and obese mice. For example, overexpression of orexin decreases BW of mice fed a low-fat-diet or HFD, but deletion of Ox2R only abolishes the effect in mice on HFD ${ }^{10}$.

Ox1R signaling in serotonergic cells protects against HFDinduced insulin resistance, due to changes in peripheral glucose uptake but not hepatic gluconeogenesis. Specifically, Ox1R signaling in serotonergic neurons activates BAT thermogenesis and glucose uptake. Ox1R deletion in serotonergic cells of obese mice resulted in larger lipid droplets in BAT and increased BAT weight. BAT whitening attracts immune cells and tissue chronic inflammation, which further increases insulin resistance, under obese conditions ${ }^{39-42}$. Mitochondria are in an equilibrium of fission and fusion, and the mitochondrial elongation/fusion facilitates oxidative phosphorylation that produces ATP from glucose $\mathrm{e}^{43-45}$. We find impaired mitochondrial function, including markers of reduced mitochondrial fusion, oxidative phosphorylation, lipid metabolism, and thermogenesis in BAT of obese mice that lack Ox1R in serotonergic neurons, suggesting that the capability of BAT to utilize glucose and fatty acids for thermogenesis and ATP production are both reduced. In line with this, BAT glucose uptake under steady-state conditions in hyperinsulinemic-euglycemic clamp studies is decreased in obese Ox1R ${ }^{\triangle S E R T}$ mice. Previous studies reported that BAT thermogenesis is activated by both the serotonin and the orexin systems. Orexin knockout mice display impaired thermogenesis due to the inability of brown preadipocytes to differentiate ${ }^{46}$. Another study fails to find detectable abnormalities in BAT development of orexin-deficient mice, and predicts that orexin controls BAT thermogenesis via a central pathway, based on the data that Ox1R is expressed low and $\mathrm{Ox} 2 \mathrm{R}$ is undetectable in $\mathrm{BAT}^{15}$.

Serotonergic neurons in the rostral $\mathrm{RPa}$ play a key role in the control of BAT thermogenesis ${ }^{26}$. We find abundant orexinergic fibers innervating $\mathrm{RPa}$, and optogenetic activation of these orexinergic fibers improves glucose tolerance. Ox1R but not $\mathrm{Ox} 2 \mathrm{R}$ is expressed in serotonergic neurons in $\mathrm{RPa}$, and consistent 
with this, BAT morphology and thermogenic factors remained unchanged when $\mathrm{Ox} 2 \mathrm{R}$ is specifically deleted in serotonergic neurons. Therefore, our data suggest that Ox1R in serotonergic neurons in $\mathrm{RPa}$ is crucial to mediate the activation of BAT thermogenesis by orexin and serotonin systems, and thus to improve glucose metabolism.

Glucose uptake in skeletal muscle is also reduced in serotonergic-specific Ox1R-deleted obese mice. A previous study reported that orexin injection in the ventromedial hypothalamus stimulates skeletal muscle glucose uptake via activation of the sympathetic nervous system ${ }^{47}$. Indeed, orexin and serotonin systems both regulate the autonomic system ${ }^{48,49}$. However, further investigations are clearly needed to understand the mechanisms of Ox1R signaling in serotonergic neurons in the stimulation of skeletal muscle glucose uptake.

In contrast to Ox1R, Ox2R signaling in serotonergic neurons impairs glucose tolerance and contributes to insulin resistance induced by HFD feeding. The dominant Ox2R signaling in DRV could be important in glucose intolerance and insulin resistance upon HFD feeding. The impairment of glucose tolerance and insulin sensitivity by $\mathrm{Ox} 2 \mathrm{R}$ in serotonergic neurons is mainly due to the impaired insulin-stimulated suppression of gluconeogenesis in liver. Although orexin deleted mice exhibit late-onset obesity, acute i.c.v. injection of orexin increases blood glucose levels ${ }^{14}$. In line with this, we find that optogenetic activation of orexin neurons in LH induces significant impairment of glucose tolerance and a trend toward impairment of insulin sensitivity by GTT and ITT. Central application of orexin increases the expression of G6Pase and Pepck in liver and the increase of Pepck is abolished by the deficiency of Ox2R but not Ox1R, suggesting that $\mathrm{Ox} 2 \mathrm{R}$ mainly mediates the orexin-induced increase of gluconeogenesis in liver ${ }^{14}$. This supports our hypothesis that Ox2R signaling in serotonergic neurons, especially in DRV, potentially plays an important role in orexin-induced glucose elevation via increasing liver gluconeogenesis.

The orexin system shows a circadian rhythm and is also changed according to the nutrition state, which is related to its bidirectional regulation of blood glucose ${ }^{12,14}$. The differential roles of Ox1R and Ox2R in serotonergic neurons could partially explain the underlying mechanisms of this bidirectional regulation. Obese $\mathrm{Ox} 1 \mathrm{R}^{\triangle \mathrm{SERT}}$ and Ox2R $\mathrm{R}^{\triangle \mathrm{SERT}}$ mice exhibit opposite changes in GIR in euglycemic-hyperinsulinemic clamp experiments, for which mice are fasted for $4 \mathrm{~h}$ in the morning. Obese Ox1R ${ }^{\triangle S E R T}$ mice show impaired glucose tolerance in GTT after a 6-h (in the morning) but not 16-h (overnight) fasting period, while obese $\mathrm{O} 2 \mathrm{R}^{\triangle \mathrm{SERT}}$ mice exhibit a more significant improvement in glucose tolerance in GTT after a 16-h fasting period compared to 6-h fasting. Ox1R and Ox2R signaling in serotonergic cells seems to dominantly regulate glucose metabolism under a shorter fasting condition at light phase or after a longer fasting time at dark phase, respectively. On the other hand, conditional knockout of orexin receptors in serotonergic neurons of obese mice significantly alters glucose tolerance during a GTT and alters glucose uptake and gene/protein expression levels in peripheral tissue and insulin sensitivity during euglycemic-hyperinsulinemic clamp experiments under fasting conditions, while insulin tolerance during ITT, BW and body composition under random-fed conditions remained unaltered. This indicates that orexin signaling in serotonergic neurons could be more relevant under nutritionrestricted conditions with respect to the control of glucose metabolism. Moreover, in random-fed obese Ox1R ${ }^{\Delta S E R T}$ mice (21-wk old), impaired BAT function was detected at molecular and morphological levels. These clear changes in BAT could be lateonset and the time of HFD exposure may not have been sufficient to translate these effects into significant changes in BW or body composition, while compensation of other peripheral organs is also possible. Clearly, further well-designed studies are needed to investigate the underlying mechanisms of the above findings.

Orexin acutely promotes feeding but in long term also promotes energy expenditure, in part by regulating spontaneous physical activity and supporting a sympathetic tone, which dominates in the control of energy balance. The serotonin system is also well known to be involved in the control of food intake and body weight ${ }^{24,25}$. However, in our study, deletion of orexin receptors in serotonergic neurons fails to alter locomotor activity or feeding behavior under random-fed conditions. This suggests that the regulatory role of orexin signaling in serotonergic neurons in glucose metabolism and energy homeostasis is independent of feeding or spontaneous physical activity.

We found intermingled and distinct $\mathrm{LH}$ cells projecting to DR or RPa. The boundaries of the heterogeneous $\mathrm{RN}$ subregions are not clear and their projections overlap, so it is important to define serotonergic neuron subtypes by both molecular and spatial specificity. Most strategies in previous reports about the differential functions of subregions of RN used micro-injections of drugs targeting the serotonergic system or analyzed serotonergic neuronal activity in experimental disease models ${ }^{50}$. The specific roles of subtypes of DR serotonergic neurons in energy homeostasis have been rarely studied so far. A recent study using viralgenetic methods shows that the subcortical-projecting serotonergic neurons preferentially localize in DRD and the corticalprojecting ones localized more in DRV. Further, they could show that the subcortical amygdala- and prefrontal-cortex-projecting DR neurons exhibit opposite responses to aversive stimuli and differentially regulate behaviors upon exposure to stress ${ }^{51}$. Our analysis reveals that the most differently expressed gene between Ox1R- and Ox2R-dominant serotonergic neurons is VGLUT3, and suggests more Ox2R-dominant serotonergic neurons are glutamatergic than Ox1R-dominant neurons. VGLUT3 has been shown to be higher expressed in serotonergic neurons in DRV compared to those in DRD, and it increases serotonin-1A receptor (5HT-1A)-mediated neurotransmission in $\mathrm{RN}$ and accelerates serotonin release at a specific subset of serotonergic nerve terminals ${ }^{51,52}$. Furthermore, DR neurons expressing vesicular transporters for gamma-aminobutyric acid (GABA), Vgat (Slc32a1), or for glutamate, VGLUT3, were shown to increase or suppress food intake, respectively ${ }^{53}$. According to scRNA-seq data, GABA receptors (Gabbr1 and Gabrg3) and VGLUT3 are enriched in different subtypes of serotonergic neurons, potentially suggesting that different subtypes of serotonergic neurons modulate food intake via distinct mechanisms $\mathrm{s}^{30,53}$. Ox1R and Ox2R signaling relate to both the spatial and neurochemical heterogeneity of serotonergic neurons in DR. Together with our data, these reports support the hypothesis that serotonergic neurons in DRD and DRV have distinct roles in the modulation of glucose metabolism and energy homeostasis.

Only Ox1R but not Ox2R are expressed in serotonergic neurons in MRV. Interestingly, Ox $2 \mathrm{R}$ is abundantly expressed in non-Sert-expressing neurons in MRV, which implicates the possibility of their crosstalk with Ox1R-expressing serotonergic neurons in the same area. Serotonergic neurons in DR and MR reciprocally connect to neurons in the hypothalamus (HTN), implying a functional role in regulating energy metabolism. The projections of DR and MR were mainly studied with neuronsubtype-unspecific tracing methods, and are considered more diverse than their inputs ${ }^{54,55}$. Distinct roles for MR and DR serotonergic neurons have been described and some researchers even suggest antagonism between them ${ }^{56,57}$. It will be interesting to elucidate the functional roles of orexin receptor signaling in this region in future studies.

Collectively, our study reveals differential expression patterns and functional roles of Ox1R and Ox2R signaling in serotonergic 
neurons in the control of peripheral glucose metabolism, BAT thermogenesis, and liver gluconeogenesis. Further detailed studies to understand this complex neuronal network and underlying cellular mechanisms will help to develop possible therapies targeting the orexin or serotonin systems for obesity.

\section{Methods}

Animal care. All animal procedures were conducted in compliance with protocols approved by the local government authorities (Bezirksregierung Cologne, Germany) and were in accordance with National Institutes of Health guidelines. Permission to maintain and breed mice as well as all for experimental protocols in this study was issued by the Department for Environment and Consumer Protection - Veterinary Section, Cologne, North Rhine-Westphalia, Germany (8402.04.2015.A335). Mice were housed in groups of $3-5$ at $22^{\circ} \mathrm{C}-24^{\circ} \mathrm{C}$ using a $12-\mathrm{h}$ light/12-h dark cycle, with humidity of $50-70 \%$. Animals had ad libitum access to water and food at all times, and food was only withdrawn if required for an experiment. Animals were fed a NCD (ssniff ${ }^{\mathrm{R}} \mathrm{R} / \mathrm{M}-\mathrm{H}$ Phytoestrogenarm), which contains $57 \mathrm{KJ} \%$ calories from carbohydrates, $34 \mathrm{KJ} \%$ calories from protein, and 9 KJ\% calories from fat, a CD (ssniff ${ }^{\mathrm{R}}$ EF D12450B * mod. LS), which contains $67 \mathrm{KJ}$ $\%$ calories from carbohydrates, $20 \mathrm{KJ} \%$ calories from protein and $13 \mathrm{KJ} \%$ calories from fat, or a HFD (ssniff ${ }^{\mathrm{R}}$ EF acc. D12492 (I) mod.), which contains $21 \mathrm{KJ} \%$ calories from carbohydrates, $19 \mathrm{KJ} \%$ calories from protein and $60 \mathrm{KJ} \%$ calories from fat.

$\mathrm{BL} / 6$ mice were purchased from Charles River, France. tdTomato $\mathrm{fl} / \mathrm{fl}$ mice were purchased from The Jackson Laboratory (B6;129 S6-Gt(ROSA)26Sor ${ }^{\text {tm } 9 \text { (CA6- }}$ tdTomato)Hze, stock No: 007905), and have been previously described ${ }^{29}$. Slc6a4-Cre (Sert-Cre) mice were imported from the Mutant Mouse Resource \& Research Center supported by NIH (stock number: 017260-UCD) ${ }^{58}$. ChR2-tdTomato fl/fl mice were obtained from The Jackson laboratory (B6; 129S-Gt(ROSA) 26Sortm32(CAG-COP4*ChR2(H134R)tdTomato, Ai27, stock No: 012567) ${ }^{59}$

Generation of $\operatorname{Ox} 1 \mathbf{R} \mathbf{f l} / \mathbf{f l}$ mice and $\operatorname{Ox2R} \mathbf{f l} / \mathbf{f l}$ mice. Ox1R flox $(O x 1 R$ fl/fl, Supplementary Fig. 2a-d) and Ox2R flox (Ox2R fl/fl, Supplementary Fig. 2e-h) mice were generated in our facility.

To create a conditional Ox1R allele, a targeting vector was constructed which flanks exon 4,5 , and 6 of the Ox1R gene (Hcrt1) by loxP sites by inserting the two homology arms and the loxP-flanked gene segment into the GK12TK vector using standard cloning techniques. The $4.3 \mathrm{~kb}$ short arm of homology was amplified using primers Ox5SA (5'-GCGGCCGCTCAGCACGACATGCTCAGAGA-3') and Ox3SA (5'-GCGATCGCATTATCTGCACTGCGAATATAGC-3'). Primers Flox5 (5'-GGCGCGCCTATGTTCCAATGTCAGGGACC-3') and Flox3 (5'-GGCCGGCC ACCCATTCTTGCTGGTGAGGT- $3^{\prime}$ ) were used in a PCR reaction to amplify the $2.2 \mathrm{~kb}$ loxP-flanked gene segment. The $5 \mathrm{~kb}$ long arm of homology was amplified by PCR using primers Ox5LA (5'-AAGCTTATGAAGGGAAGGCCCAGGACT-3') and Ox3LA (5'-TTAATTAACCTCTGTTTCCTGACTTAGAG-3'). C57/BL6derived Bruce- 4 embryonic stem cells were transfected with the linearized targeting vector and subsequently selected for G418 and GANC resistance. Four hundred single clones were isolated from which three were shown to contain the external loxP-site using probe $\mathrm{B}$ that was amplified by PCR using primers S5C (5'-AGT TGTGAGCATGTGCAAGG- ${ }^{\prime}$ ) and S3C (5'-CTCTAAACATCACATATC- ${ }^{\prime}$ ). Single integration of the targeting vector was confirmed by using a probe in Southern Blot analysis against the neomycin resistance gene at HindIII digested genomic clonal DNA resulting in a single $11.6 \mathrm{~kb}$ band. Positive clones were injected into $\mathrm{CB} 20$ blastocysts to obtain chimeric mice $\left(\mathrm{Ox} 1 \mathrm{R}^{\mathrm{FL}-\mathrm{neo}}\right)$, which were further intercrossed with Flp-deleter mice ${ }^{60}$ to achieve both, germline transmission and removal of the FRT flanked neo resistance cassette.

To create a conditional Ox $2 \mathrm{R}$ allele, a targeting vector was constructed which flanks exon 2 of the Ox2R gene (Hcrt2) by loxP sites by inserting the two homology arms and the loxP-flanked gene segment into the GK12TK vector using standard cloning techniques. The $1.6 \mathrm{~kb}$ short arm of homology was amplified using primers Ox5SA (5'-GCGGCCGCAGACAAGCCTCTGGGCAAAGT- $\left.3^{\prime}\right)$ and Ox3SA (5'-CC GCGGCTTAATCTTAGC CTTGGGAGG-3'). Primers Flox5 (5'-GGCGCGCCGA CACATGCTGCTATACCTAT- $\left.3^{\prime}\right)$ and Flox $3\left(5^{\prime}-\right.$ GGCCGGCCTCATTAGTTTG TTCAGATCATCTC- $3^{\prime}$ ) were used in a PCR reaction to amplify the $0,8 \mathrm{~kb}$ loxPflanked gene segment. The $5 \mathrm{~kb}$ long arm of homology was amplified by PCR using primers Ox5LA (5'-CTTAAGTTAAGACATCCCTAGCTCAAA-3') and Ox3LA (5'-TTAATTAACACCTCCAAAGGACCTGAATT-3'). C57/BL6-derived Bruce-4 embryonic stem cells were transfected with the linearized targeting vector and subsequently selected for G418 and GANC resistance. Single clones were isolated from which 2 were shown to contain the external loxP-site using probe B that was amplified by PCR using primers S5C (5'-AACCCATACCCTGACCCTTC- $\left.3^{\prime}\right)$ and S3C (5'-TTTCCAAAATGCCTTTCCAG-3 $\left.{ }^{\prime}\right)$. Single integration of the targeting vector was confirmed by using a probe in Southern Blot analysis against the neomycin resistance gene at HindIII digested genomic clonal DNA resulting in a single $12.7 \mathrm{~kb}$ band. Positive clones were injected into CB20 blastocysts to obtain chimeric mice $\left(\mathrm{O} \times 2 \mathrm{R}^{\mathrm{FL}-\mathrm{neo}}\right)$, which were further intercrossed with Flp-deleter mice ${ }^{60}$ to achieve both, germline transmission and removal of the FRT flanked neo resistance cassette.
Generation of Orexin-IRES-Cre mice. Orexin-IRES-Cre mice were generated, validated, and kindly provided by Drs. D.K., T.E.S., and B.B.L. Briefly, a BAC clone containing the mouse Ore/Hcrt genomic sequence was used to generate the targeting construct. A PCR amplicon containing the IRES-Cre-FRT-NEO-FRT cassette flanked by $70 \mathrm{bp}$ of homologous sequence at both ends, which matched the 3 end UTR site of Orx/Hcrt allele, was constructed and transformed into electrocompetent DY380 cells that had been previously transformed with the aforementioned Ore $/ \mathrm{Hcrt}$ BAC ${ }^{61}$, followed by temperature-induced recombineering. A targeting construct was derived from this modified BAC spanning the region $5 \mathrm{~kb}$ upstream of the IRES site and $2 \mathrm{~kb}$ downstream of the Cre site inserted into $3^{\prime}$-end genomic region. The resulting targeting construct was then electroporated into mouse W4/129S6 embryonic stem (ES) cells and injected into blastocysts to generate chimeras. Male chimeras were bred to mice bearing a flp-recombinase transgene to remove the neomycin selection marker and to Ai14 cre reporter line (Jax 007908) to verify cre activity in the hypothalamus. Detailed description and characterization of this mouse line will be reported separately (Howard et al. unpublished)

GTTs and ITTs. GTTs were performed on 12- or 15-week-old male animals that had been fasted for $6 \mathrm{~h}$ or overnight for $16 \mathrm{~h}$ from $8: 30$ am or $6 \mathrm{pm}$, respectively. ITTs were performed on 11-week-old random-fed male mice around 9 am. Animals received an intraperitoneal injection of $20 \%$ glucose $(10 \mathrm{ml} / \mathrm{kg}$ body weight; $\mathrm{KabiPac})$ or insulin $(0.75 \mathrm{U} / \mathrm{kg}$ body weight; Sanofi-Aventis) into the peritoneal cavity, respectively. Glucose levels were determined in blood collected from the tail tip using an automatic glucose monitor (Contour ${ }^{\mathrm{R}}$, Bayer), immediately before and 15,30 , and $60 \mathrm{~min}$ after the injection, with an additional value determined after 120 min for the GTTs.

Relative mitochondrial DNA quantification. BAT was dissected from 21-weekold male HFD-fed mice. Total DNA from BAT was isolated and the DNA level was detected with Power SYBR ${ }^{\mathrm{R}}$ Green PCR Master Mix (ThermoFisher Scientific). Primers for mitochondrial $N d 2$ and nuclear $N d u f$ were from the publication by Jais et al. ${ }^{62}$, and primers for mitochondrial $D$-loop region (fwd: $5^{\prime}$-GGTTCTTACT TCAGGGCCATCA-3, rev: 5'-GATTAGACCCGATACCATCGAGAT-3') were designed with Primer Express software (Applied Biosystems). The relative mitochondrial DNA content to the nuclear DNA was determined with $2^{-\mathrm{ddCT}}$ method.

Analysis of gene expression. BAT was dissected from 21-week-old male HFD-fed mice. Total RNA from BAT was isolated using the RNeasy ${ }^{\mathrm{R}}$ Lipid Tissue Mini Kit (Qiagen). cDNA was prepared using the High-Capacity cDNA Reverse Transcription Kit (Applied Biosystems). mRNA levels were then determined with realtime quantitative RT-PCR using TaqMan $^{\mathrm{R}}$ Gene Expression Master Mix (Ther moFisher Scientific) and the respective probes, according to the manufacturer's instructions. Gapdh was used as the internal control. Relative expression was determined using a comparative method $\left(2^{-\mathrm{ddCT}}\right)$. Probes purchased from ThermoFisher Scientific are shown in Supplementary Table 1.

RNA sequencing of BAT. BAT was dissected at the end of hyperinsulinemiceuglycemic clamp experiments. The tissue was frozen at $-80^{\circ} \mathrm{C}$ until the RNA was extracted with DNase digestion using the RNeasy ${ }^{\mathrm{R}}$ Lipid Tissue Mini Kit (Qiagen) and RNase-Free DNase Set (Qiagen), following the user's manual. RNA integrity was detected with the Agilent RNA 6000 Nano Kit (5067-1511, Agilent Technologies) and the Agilent 2100 Bioanalyzer. RNA libraries were prepared using the Illumina ${ }^{\circledR}$ TruSeq ${ }^{\circledR}$ mRNA stranded sample preparation Kit. Library preparation started with $1 \mu \mathrm{g}$ total RNA. After poly-A selection (using poly-T oligo-attached magnetic beads), mRNA was purified and fragmented using divalent cations under elevated temperatures. The RNA fragments underwent reverse transcription using random primers. This is followed by second-strand cDNA synthesis with DNA Polymerase I and RNase $\mathrm{H}$. After end repair and A-tailing, indexing adapters were ligated. The products were then purified and amplified (14 PCR cycles) to create the final cDNA libraries. After library validation and quantification (Agilent tape station), equimolar amounts of the library were pooled. The pool was quantified by using the Peqlab KAPA Library Quantification Kit and the Applied Biosystems 7900 HT Sequence Detection System. The pool was sequenced for 35 million reads using an Illumina NovaSeq6000 instrument and a PE100 sequencing protocol.

For the statistical analysis, we applied the community-curated nfcore rnasec analysis pipeline version $1.4^{63}$. The gene-level quantification was carried out using Salmon 0.14.1 ${ }^{64}$ using the reference genome GRCm38 (https://www.ncbi.nlm.nih.gov/ assembly/GCF_000001635.20). The differential gene expression analysis was done using the DESeq2 $1.26 .0^{65} \mathrm{R}$ package and yielded 265 genes (Fig. 6e). A gene-ontology term analysis of the 265 differentially expressed genes was carried out using the clusterProfiler $3.14 .3^{66} \mathrm{R}$ package and yielded 530 differentially expressed GO-terms of class biological process. Applying the simplified method of clusterprofiler, which removes similar gene ontologies, yielded subsequently a list of 131 differentially expressed biological process terms. Figure $6 f$ shows the top 15 differentially expressed terms of that list.

Western blotting. BAT was dissected from 21-week-old male mice on HFD and homogenized in RIPA buffer (Sigma-Aldrich) added with cOmplete ${ }^{\mathrm{TM}}$ Protease 
Inhibitor Cocktail (Roche), using a FastPrep instrument (MP Biomedicals) and bulk beads (Bertin Corp.). The protein samples were separated on $10 \%$ Criterion $^{\mathrm{TM}}$ TGX $^{\text {TM }}$ Precast Midi Protein Gel (BioRad) and transferred with Trans-Blot ${ }^{\mathrm{R}}$ Turbo $^{\text {TM }}$ Midi PVDF Transfer pack (BioRad). After blocking with 5\% non-fat milk or a blocking reagent (Roche) in Tris-buffered saline containing $0.1 \%$ Tween- 20 (TBST) at room temperature (RT) for $1 \mathrm{~h}$, the membranes were incubated overnight at $4{ }^{\circ} \mathrm{C}$ with antibodies raised against $\mathrm{pSer}^{473}$-Akt $(1: 1000$, \#4060, rabbit mAb, Cell Signaling Technology), Akt (1:1000, \#4685, rabbit mAb, Cell signaling Technology), G6Pase (1:250, sc-25840, rabbit pAb, Santa Cruz Biotechnology), UCP-1 (1:200, sc-6528, goat pAb, Santa Cruz Biotechnology), Tom20 (1:100, sc17764, mouse mAb, Santa Cruz Biotechnology), OPA1 (1:1000, 612607, mouse mAb, BD Biosciences), MFN1 (1:1000, ab57602, mouse mAb, Abcam), MFN2 (1:1000, ab56889, mouse mAb, Abcam), DRP1 (1:1000, \#8570, rabbit mAb, Cell Signaling Technology), MFF (1:2000, 17090-1-AP, rabbit pAb, Proteintech ${ }^{\mathrm{R}}$ ), FIS1 $\left(1: 500,10956-1-A P\right.$, rabbit pAb, Proteintech $\left.{ }^{R}\right)$ or complex I-V subunits in the respiratory chain (1:1000, Total OXPHOS Rodent WB Antibody Cocktail, containing 5 mouse mAbs, ab110413, Abcam). Calnexin (1:5000, 208,880, rabbit pAb, Calbiochem ${ }^{\mathrm{R}}$ ) was used as the loading control. The secondary antibodies (1:3000) were then incubated at RT for $1 \mathrm{~h}$. Peroxidase conjugate goat anti-rabbit IgG (A6154), goat anti-mouse IgG (A4416) and mouse anti-goat IgG (A9452) were purchased from Sigma-Aldrich. The signal was detected with SuperSignal ${ }^{\text {wo }}$ West Dura Extended Duration Substrate (ThermoFisher Scientific), using films or camera (Vilber Smart Imaging). Films were developed with X-ray film processor Curix 60 (AGFA Healthcare). When necessary, membranes were stripped in stripping buffer $\left(62.5 \mathrm{mM}\right.$ Tris pH $6.8,2 \% \mathrm{SDS}, 0.7 \% \beta$-mercapotethanol; $56^{\circ} \mathrm{C}$, $30 \mathrm{~min}$ ), washed twice in TBST, blocked in blocking buffer, and reprobed with the respective primary antibodies. Band densities were analyzed with Image J/FIJI (version $1.50 \mathrm{~d}$, http://imagej.net). Data were normalized to protein expression levels in the control group.

Imaging. BAT was post-fixed after sacrificing. Brains were dissected from perfused mice, except for optogenetic experiments. Anesthetized mice were perfused with $0.9 \%$ saline, followed by $4 \%$ paraformaldehyde (PFA) in $0.1 \mathrm{M}$ phosphate-buffered saline (PBS). Brains were removed, post-fixed in 4\% PFA for the indicated time, and dehydrated in $20 \%$ sucrose in $0.1 \mathrm{M}$ PBS overnight. After embedding in Leica Tissue Freezing medium, brains were stored at $-80^{\circ} \mathrm{C}$ until cutting. For optogenetics, head was cut and directly put in $4 \% \mathrm{PFA}$ at $4{ }^{\circ} \mathrm{C}$ for 7 days until brain dissection, and then brains were dehydrated and processed as above. Each brain/ mouse represents one biological replicate, and at least two images, as technical replicates, were taken for each brain/mouse.

Haematoxylin and eosin (HeE) staining of BAT. BAT was dissected from 21-weekold male mice on a HFD. It was post-fixed in $4 \%$ PFA at $4{ }^{\circ} \mathrm{C}$ for more than $16 \mathrm{~h}$ and embedded with pre-set program in Shandon ${ }^{\mathrm{TM}}$ Excelsior ${ }^{\mathrm{TM}}$ ES Tissue Processor Accessories (ThermoFisher Scientific). In general, tissue was put in formalin for $1 \mathrm{~h}$ twice, $70 \%$ ethanol for $2 \mathrm{~h}, 96 \%$ ethanol for $2 \mathrm{~h}$ twice, $100 \%$ ethanol for 1 or $2 \mathrm{~h}$ three times, xylene for 1 or $2 \mathrm{~h}$ three times, and liquid wax for $1 \mathrm{~h}$ to $1.67 \mathrm{~h}$ three times, at $45^{\circ} \mathrm{C}$. Tissues were then embedded in blocks using Leica EG1150 H Heated Paraffin Embedding Module and Leica EG1150 C Cold Plate for Modular Tissue Embedding System. Sample blocks were stored at RT until cutting. Slices $(5 \mu \mathrm{m})$ were cut with Leica RM2255 Fully Automated Rotary Microtome. Slices were deparaffinized with xylene for $20 \mathrm{~min}$, put into isopropanol for $2 \mathrm{~min}$, gradually hydrated with diluted ethanol and water, stained with Mayer's haematoxylin solution (Sigma-Aldrich) followed by eosin solution (Sigma-Aldrich) after washing, washed in water, gradually dehydrated in diluted ethanol, put in xylene and finally mounted with Cytoseal XYL (ThermoFisher Scientific). Slides were stored at RT, and imaged with Zeiss Imager M2 microscope and the software Zen 2 (Carl Zeiss AG).

Electronic microscope images of BAT. BAT samples were isolated from HFD-fed male mice (12-15 weeks) and fixed in $2 \%$ glutaraldehyde and $2 \%$ formaldehyde in $0.1 \mathrm{M}$ cacodylate buffer $(\mathrm{pH} 7.2)$ for $48 \mathrm{~h}$ at $4{ }^{\circ} \mathrm{C}$. Samples were rinsed in $0.1 \mathrm{M}$ cacodylate buffer ( $\mathrm{pH} 7.2$ ), post-fixed with $1 \% \mathrm{OsO} 4$ in $0.1 \mathrm{M}$ cacodylate buffer $(\mathrm{pH} 7.2)$ for $3 \mathrm{~h}$ at $4{ }^{\circ} \mathrm{C}$, dehydrated through an ethanol series, transferred to propylene oxide, and embedded in epoxy resin. Semi-thin sections of $500 \mathrm{~nm}$ were cut, followed by cutting into ultrathin sections of $70 \mathrm{~nm}$, with a diamond knife (Diatome, Biel, Switzerland) on an ultramicrotome (EM-UC6, Leica). Ultrathin sections were place on a 100 mesh grid, contrasted with $1.5 \%$ uranyl acetate for $15 \mathrm{~min}$ at $37^{\circ} \mathrm{C}$, put in lead citrate for $4 \mathrm{~min}$ after washing, and dried after additional washing. Images were taken on a transmission electron microscope (Zeiss EM109 and JEOL JEM 2100Plus) at RT. Mitochondrial size and aspect ratio were analyzed with Image J/FIJI (version 1.50d).

Immunostaining in lateral hypothalamus and raphe nuclei. Brains were post-fixed for $6 \mathrm{~h}$ at $4{ }^{\circ} \mathrm{C}$, and cut $(30 \mu \mathrm{m})$ with Leica CM3050 S Research Cryostat. Sections were incubated in $0.3 \%$ glycine for $10 \mathrm{~min}$ after washing in $0.1 \mathrm{M}$ PBS for $2 \times 10 \mathrm{~min}$. After washing in PBS for another $10 \mathrm{~min}$, sections were incubated in $0.03 \%$ SDS (in PBS) for 10 min before they got blocked with 3\% donkey serum (in PBS, $0.25 \%$ Triton X-100) for $1 \mathrm{~h}$ at RT. Afterwards, they were incubated with primary antibodies, including goat anti-orexin A $(1: 250$, sc- 8070 , goat pAb, Santa
Cruz Biotechnology), chicken anti-GFP (1:1000, ab13970, chicken pAb, Abcam), rabbit anti-TPH2 (1:1000, \#51124, rabbit mAb, Cell Signaling Technology) and/or rabbit anti-serotonin (1:400, S5545, rabbit pAb, Sigma-Aldrich), for overnight at RT, washed in PBS for $3 \times 10 \mathrm{~min}$, and incubated with secondary antibodies (1:500), including Alexa Fluro 594 donkey anti-goat, FITC donkey anti-chicken, Alexa Fluro 488 donkey anti-rabbit, Alexa Fluro 647 donkey anti-rabbit (a11058, sa 1-7200, a21206 and a31573, Invitrogen), for $1 \mathrm{~h}$ at RT. After washing in PBS for $3 \times 10 \mathrm{~min}$, slices were mounted and covered with VECTASHIELD Antifade Mounting Medium with DAPI (Vector Laboratories). Slices were stained together at one time for each experiment to have identical conditions for comparable signals. Slides were stored at $4{ }^{\circ} \mathrm{C}$ until imaging. Images were obtained with confocal laser scanning microscope Leica TCS SP8 and manually analyzed with Image J/FIJI (version 1.50d).

RNAscope fluorescent in situ hybridization in lateral hypothalamus and raphe nuclei. Brains from BL/6 mice (14 weeks, fasted for $6 \mathrm{~h}$ ) on CD/HFD, and brains from Sert ${ }^{\text {tdTomato, }}$ Ox $1 \mathrm{R}^{\Delta S E R T / t d T o m a t o}$, and Ox $2 \mathrm{R}^{\Delta S E R T / t d T o m a t o}$ mice

(13-18 weeks) on NCD were post-fixed for $20-22 \mathrm{~h}$ at RT and cut $(20 \mu \mathrm{m})$. Slides were stored at $-80^{\circ} \mathrm{C}$ until staining. All reagents were purchased from Advanced Cell Diagnostics and the staining was performed with the RNAscope Multiplex Fluorescent v2 kit and RNAscope 4-Plex Ancillary Kit (ACD, Advanced Cell Diagnostics) according to the user manual. Probes for Ox1R (Hcrtr1, 471561-C3, $\mathrm{ACD}$ ) and $\mathrm{Ox} 2 \mathrm{R}$ (Hcrtr2, 471551, ACD) were designed according to the loxPflanked region. The probes for tdTomato (tdTomato, 317041-C2, and C3), c-Fos (c-Fos, 316921-C4), TPH2 (Tph2, 318691), Pet1 (Fev, 413241-C2), SERT (Slc6a4, 315851-C2), VGLUT3 (Slc17a8, 431261-C2), and orexin (Hcrt, 490461-C2) were commercially available by ACD. In brief, slides were briefly washed in diethylpyrocarbonate (DEPC)-treated Millipore water, air dried and then dried at $60^{\circ} \mathrm{C}$ overnight. On the second day, slides were treated with hydrogen peroxide $\left(\mathrm{H}_{2} \mathrm{O}_{2}\right)$ for 10 min at RT, washed in water and boiled in Target Retrieval solution (around $99.4^{\circ} \mathrm{C}$ ) for $8-10 \mathrm{~min}$. After a brief washing in water and dehydration in absolute ethanol, slides were incubated with protease IV for $30 \mathrm{~min}$ at RT. Slides were washed again in water and hybridized with the mixture of probes in different channels for $2 \mathrm{~h}$ in a humidified chamber at $40^{\circ} \mathrm{C}$. Afterwards, the hybridization was amplified with AMP 1 for 30 min, AMP 2 for 30 min, and AMP 3 for 15 min. The signal was then developed for each channel. For example, for channel 1, slides were incubated with HRP-C1 for $15 \mathrm{~min}$, the fluorophore for $30 \mathrm{~min}$, and HRP blocker for $15 \mathrm{~min}$. All amplification and development were performed at $40^{\circ} \mathrm{C}$, and $2 \times 2$ min of washing in ACD wash buffer was performed after each step. Finally, the slides were counterstained with DAPI for 1 min, mounted with Prolong ${ }^{\mathrm{TM}}$ Gold Antifade reagent with DAPI (Invitrogen), and covered with coverslips. For the RNAscope-immunostaining combined experiments, after the last washing step of RNAscope, slides were directly incubated with blocking buffer and processed with routine immunostaining methods.

Slides were dried and stored at $4{ }^{\circ} \mathrm{C}$. Imaging was performed with confocal laser scanning microscope Leica TCS SP8. The raphe nuclei were automatically analyzed with the software Halo 2.0 (Indica Labs) in Fig. 1a-f and Fig. 2. Serotonergic neurons were identified according to the fluorescence intensity of tdTomato, and Ox1R and Ox2R signal in serotonergic neurons was detected and analyzed. Other images wer/e manually analyzed with Image J/FIJI (version 1.50d).

Food intake and locomotor activity. Male mice (20-week old) on NCD and HFD under random-fed conditions were analyzed. Food intake, locomotor activity, and indirect calorimetry measurements were made in a PhenoMaster System (TSE Systems) as previously described ${ }^{67}$

Hyperinsulinemic-euglycemic clamp studies. Surgical implantation of catheters in the jugular vein was performed in $\sim 17$-week-old HFD-fed male mice as previously described ${ }^{68}$. Mice recovered from surgery for $\sim 1$ week and only mice that regained at least $90 \%$ of pre-surgery bodyweight were included in further experiments. After fasting for $4 \mathrm{~h}$, mice were placed into chambers, which allow them to move freely throughout the clamp experiment. After a bolus infusion $(0.8 \mu \mathrm{Ci})$ of $\mathrm{D}-\left[3{ }^{3} \mathrm{H}\right]$ glucose (PerkinElmer) tracer solution, the tracer was infused continuously $(0.04 \mu \mathrm{Ci} / \mathrm{min})$. After basal infusion, blood was collected for the determination of basal parameters. Then, insulin (Novo Nordisk) was infused at a fixed rate $(6 \mu \mathrm{U} / \mathrm{g} /$ min) during the clamp experiment. Blood glucose levels were determined every 10 min (Glucose 201 RT System, HemoCue ${ }^{\mathrm{R}}$ ), and the infusion of $40 \%$ glucose (bela-pharm) was adjusted to maintain physiological blood glucose levels $(120-160 \mathrm{mg} / \mathrm{dl})$. Steady state was ascertained when glucose measurements were constant for at least $30 \mathrm{~min}$ at a fixed glucose infusion rate and was achieved within 100 to $120 \mathrm{~min}$ of the clamp experiment. At the end of the steady state, a bolus (10 $\mu \mathrm{Ci})$ of 2-deoxy-D-[1-14 C]-glucose (2DG; American Radiolabeled Chemicals, Inc.) was infused. Blood was collected 2, 7, 15, 25, and 35 min after the bolus. At the end of the experiment, mice were sacrificed and tissues were dissected. Plasma was stored at $-20^{\circ} \mathrm{C}$, and liver, SM, WAT, and BAT were stored at $-80^{\circ} \mathrm{C}$ until further analysis.

Plasma $\left[3-{ }^{3} \mathrm{H}\right]$ glucose radioactivity of basal and steady state was measured and glucose turnover rate $\left(\mathrm{mg} \times \mathrm{kg}^{-1} \times \mathrm{min}^{-1}\right)$ was calculated as previously described $^{68}$. Plasma $2-\left[1-{ }^{14} \mathrm{C}\right]$-Deoxy-D-glucose radioactivity was directly measured in the liquid scintillation counter. WAT, BAT, and SM lysates were 
processed through ion-exchange chromatography columns (Poly-Prep Prefilled Chromatography Columns, AG1-X8 formate resin, 200-400 mesh dry; Bio-Rad) to separate 2DG from 2DG-6- phosphate (2DG6P). In vivo glucose uptake for WAT, $\mathrm{BAT}$, and skeletal muscle $\left(\mathrm{nmol} \times \mathrm{g}^{-1} \times \mathrm{min}^{-1}\right)$ was calculated based on the accumulation of 2DG6P in the respective tissue and the disappearance rate of 2DG from plasma as described previously ${ }^{69}$. Serum human insulin concentrations at baseline levels and at the end of the clamp studies were measured with $\mathrm{DRG}^{\circledR}$ Ultra Sensitive Insulin ELISA Kit (EIA-2337).

Virus injection and optical fiber implantation. 13-week-old male Orexin-Cre mice received $1 \mathrm{mg} / \mathrm{ml}$ of tramadol in drinking water 2 days before the surgeries. On the day of surgery, mice were anesthetized with isoflurane and a bolus of buprenorphine $(0.1 \mathrm{mg} / \mathrm{kg} \mathrm{BW})$ was given (i.p.) to reduce pain. Brain regions were identified according to the atlas ${ }^{70}$. After alignment of the brain in the stereotaxic surgery platform, 1-3 small holes were drilled in the skull at specific coordinates. The channelrhodopsin 2 (ChR2) and control virus (pAAV-EF1a-double floxedhChR2(H134R)-EYFP-WPRE-HGHpA and pAAV-Ef1a-DIO EYFP, $\sim 1 \times 10^{13}$ $\mathrm{GC} / \mathrm{ml}, 333 \mathrm{nl}$, Addgene) was injected into LH unilaterally for optogenetic stimulation in LH or bilaterally for checking virus expression and optogenetic stimulation in raphe nuclei, with micropipettes pulled in house with a heating system. The coordinates from Bregma were: anterior-posterior, AP: $-1.7 \mathrm{~mm}$; mediallateral, ML: $\pm 0.9 \mathrm{~mm}$; dorsal-ventral, DV: $-5.0 \mathrm{~mm}$. The GCaMP6 virus (AAV1.Syn.Flex.GCaMP6s.WPRE.SV40, $4 \times 10^{12} \mathrm{GC} / \mathrm{ml}, 333 \mathrm{nl}$, Penn Vector Core) was injected to DR-ventral (AP: $-4.6 \mathrm{~mm}$, ML: $0 \mathrm{~mm}, \mathrm{DV}:-3.0 \mathrm{~mm}$ ) of $12-14$-week-old Sert-Cre (control), Ox1R $\mathrm{R}^{\Delta \mathrm{SERT}}$ and Ox $2 \mathrm{R}^{\triangle \mathrm{SERT}}$ mice, to specifically express GCaMP6 in serotonergic neurons. After virus injection, optical fibers (fiber core $=200 \mu \mathrm{m}$, numerical AP $=0.48$, flat tip; Doric lenses Inc.) were immediately implanted to stimulate LH (AP: $-1.7 \mathrm{~mm}$, ML: $0.9 \mathrm{~mm}, \mathrm{DV}$ : $-4.2 \mathrm{~mm}$ ) or RPa (AP: $-5.88 \mathrm{~mm}$, ML: $0 \mathrm{~mm}, \mathrm{DV}:-5.4 \mathrm{~mm}$ ), and fixed to the skull with dental acrylic (Super-Bond C\&B). Mice received a bolus of meloxicam $(5 \mathrm{mg} / \mathrm{kg} \mathrm{BW}$, s.c.), and tramadol in drinking water for $3 \mathrm{~d}$ after surgeries, to relieve pain. BW was checked twice a day. Experiments started at least 4 weeks later than virus injection to allow virus expression. The optical fiber placement was histologically verified for each mouse at the end of the experiments.

Retrograde tracing. Pre- and post-surgery treatment of mice were the same as described above. After alignment of the brain in the stereotaxic surgery platform, two small holes were drilled in the skull for DR (AP: $-4.6 \mathrm{~mm}$, ML: $0 \mathrm{~mm}$, DV: -2.8 to $-3.2 \mathrm{~mm}$ ) and RPa (AP: $-5.88 \mathrm{~mm}$, ML: $0 \mathrm{~mm}, \mathrm{DV}:-5.8$ to $-6.1 \mathrm{~mm}$ ) of 11 -week-old BL/6 male mice. The red and green fluorescent RetroBeads ${ }^{\mathrm{TM}}$ (LumaFluor, Inc.) were injected with micropipettes into DR (500 nl) or RPa $(120 \mathrm{nl})$ respectively. Five days later, mice were perfused and brains were further processed.

Optogenetic stimulation in vivo. Three weeks after virus injection, mice were transferred to the experimental cages for 1 week of habituation. At least 2 days before the experiments, a patch cord was connected to the optical fiber to allow acclimation. On the day of the experiment, a new patch cord replaced the old one. The laser was turned on $30 \mathrm{~min}$ before the injection of insulin or glucose, and the ITT and GTT were done as described above. The blue light $(473 \mathrm{~nm} ; 10 \mathrm{~ms}$ pulse, $20 \mathrm{~Hz}$ ) was turned on for $10 \mathrm{~s}$ in every $45 \mathrm{~s}$, and lasted until the end of ITT and GTT. Laser power was $20 \mathrm{~mW}$ to stimulate orexin neurons in LH and $10 \mathrm{~mW}$ to stimulate orexinergic fibers in RPa. The irradiance in the targeted region was above $2.5 \mathrm{~mW} / \mathrm{mm}^{2}$ (https://web.stanford.edu/group/dlab/cgi-bin/graph/chart.php), which was above the threshold to activate ChR2 $\left(1 \mathrm{~mW} / \mathrm{mm}^{2}\right)$ as reported before ${ }^{71}$. When measuring the response to insulin and glucose injection without laser illumination, mice were handled and experiments were done in the same way except for that the laser stayed off. There was 1 week of recovery between each experiment when using the same mice.

\section{Electrophysiology}

Animals and brain slice preparation. Experiments were performed on brain slices from 11 to 17 -week old genetically marked (with tdTomato) SerttdTomato (here referred to as control, Ctrl), Ox1R ${ }^{\Delta S E R T / t d T o m a t o ~ a n d ~ O x ~} 2 \mathrm{R}^{\Delta S E R T / t d T o m a t o ~ m a l e ~}$ mice. Animals were kept under standard laboratory conditions, with tap water and chow available ad libitum, on a $12 \mathrm{~h}$ light/dark cycle. The animals were lightly anesthetized with isoflurane (B506; AbbVie Deutschland GmbH and Co KG, Ludwigshafen, Germany) and decapitated. Coronal slices $(280 \mu \mathrm{m})$ containing DR were cut with a vibration microtome (HM-650 V; Thermo Scientific, Walldorf, Germany) under cold $\left(4{ }^{\circ} \mathrm{C}\right)$, carbogenated $\left(95 \% \mathrm{O}_{2}\right.$ and $\left.5 \% \mathrm{CO}_{2}\right)$, glycerol-based modified artificial cerebrospinal fluid $(\mathrm{GaCSF})^{72}$. GaCSF contained (in $\mathrm{mM}$ ): 244 Glycerol, $2.5 \mathrm{KCl}, 2 \mathrm{MgCl}_{2}, 2 \mathrm{CaCl}_{2}, 1.2 \mathrm{NaH}_{2} \mathrm{PO}_{4}, 10 \mathrm{HEPES}, 21 \mathrm{NaHCO}_{3}$, and 5 Glucose adjusted to $\mathrm{pH} 7.2$ with $\mathrm{NaOH}$. If not mentioned otherwise, the brain slices were continuously superfused with carbogenated aCSF at a flow rate of $\sim 2.5 \mathrm{ml} \mathrm{min}^{-1}$. aCSF contained (in mM): $125 \mathrm{NaCl}, 2.5 \mathrm{KCl}, 2 \mathrm{MgCl}_{2}, 2 \mathrm{CaCl}_{2}, 1.2$ $\mathrm{NaH}_{2} \mathrm{PO}_{4}, 21 \mathrm{NaHCO}_{3}, 10$ HEPES, and 5 Glucose adjusted to $\mathrm{pH} 7.2$ with $\mathrm{NaOH}$. To block GABAergic and glutamatergic synaptic input, the aCSF contained $10^{-4} \mathrm{M}$ PTX (picrotoxin, P1675; Sigma-Aldrich), $5 \times 10^{-6}$ M CGP (CGP-54626 hydrochloride, BN0597, Biotrend), $5 \times 10^{-5}$ M DL-AP5 (DL-2-amino-5- phosphonopentanoic acid, BN0086, Biotrend), and $10^{-5} \mathrm{M}$ CNQX (6-cyano-7nitroquinoxaline-2,3-dione, C127; Sigma-Aldrich).

Patch-clamp recordings. Perforated patch-clamp experiments were essentially performed as described previously ${ }^{73,74}$. Current-clamp recordings of tdTomatoexpressing DR neurons were performed at $\sim 32{ }^{\circ} \mathrm{C}$. Neurons were visualized with a fixed stage upright microscope (BX51WI, Olympus, Hamburg, Germany) using $\times 40$ and $\times 60$ water-immersion objectives (LUMplan FL/N $\times 40,0.8$ numerical aperture, $2 \mathrm{~mm}$ working distance; LUMplan $\mathrm{FL} / \mathrm{N} \times 60,1.0$ numerical aperture, $2 \mathrm{~mm}$ working distance, Olympus) with infrared differential interference contrast optics ${ }^{75}$ and fluorescence optics. tdTomato-expressing DR neurons were identified by their anatomical location and by their fluorescent label. Electrodes with tip resistances between 4 and $6 \mathrm{M} \Omega$ were fashioned from borosilicate glass $(0.86 \mathrm{~mm}$ inner diameter; $1.5 \mathrm{~mm}$ outer diameter; GB150-8P; Science Products) with a vertical pipette puller (PP-830; Narishige, London, UK). All recordings were performed with an EPC10 patch-clamp amplifier (HEKA, Lambrecht, Germany) controlled by the program PatchMaster (version 2.32; HEKA) running under Windows. In parallel, data were recorded using a microl410 data acquisition interface and Spike 2 (version 7) (both from CED, Cambridge, UK). Current clamp recordings were sampled at $25 \mathrm{kHz}$ and low-pass filtered at $2 \mathrm{kHz}$ with a four-pole Bessel filter.

Perforated patch experiments were conducted using protocols modified from before ${ }^{76,77}$. Recordings were performed with pipette solution containing (in $\mathrm{mM}$ ): 140 K-gluconate, $10 \mathrm{KCl}$, $10 \mathrm{HEPES}, 0.1 \mathrm{EGTA}, 2 \mathrm{MgCl}_{2}$, and $1 \%$ biocytin (B4261, Sigma) adjusted to $\mathrm{pH} 7.2$ with $\mathrm{KOH}$. ATP and GTP were omitted from the intracellular solution to prevent uncontrolled permeabilization of the cell membrane ${ }^{78}$. The patch pipette was tip filled with internal solution and backfilled with internal solution, which contained the ionophore to achieve perforated patch recordings. Amphotericin B (A4888; Sigma) was dissolved in dimethyl sulfoxide to a concentration of $200 \mu \mathrm{g} \mathrm{\mu l}^{-1}$ (DMSO; D8418, Sigma) ${ }^{79}$ and added to the internal solution. The used DMSO concentration $(0.1-0.3 \%)$ had no apparent effect on the investigated neurons. The ionophore was added to the modified pipette solution shortly before use. The final concentration of amphotericin B was $\sim 120-160 \mu \mathrm{g} \mathrm{m}^{-1}$. Amphotericin solutions were prepared from undissolved weighted samples (stored at $4{ }^{\circ} \mathrm{C}$ protected from light) on every recoding day. During the perforation process, access resistance $\left(R_{\mathrm{a}}\right)$ was monitored continuously, and experiments started after $R_{\mathrm{a}}$ had reached steady state $(\sim 15-20 \mathrm{~min})$, and the action potential amplitude was stable.

Orexin A (ab120212, Abcam) or orexin B (O6262, Sigma) was added to the aCSF and bath-applied to the cells at one concentration or as an increasing concentrations series $(1,10,100 \mathrm{nM})$ for $8-10$ min each with a perfusion rate of $\sim 2.5 \mathrm{ml} \mathrm{min}-1$.

$\mathbf{C a}^{2}+$ imaging. The experiments start at least 4 weeks after the GCaMP6 virus injection. Acute brain slices containing the DR were obtained as described for electrophysiology. Calcium dynamics were measured using the genetically encoded calcium indicator GCaMP6. The imaging setup consisted of a Zeiss AxioCam/ MRm CCD camera with a $1388 \times 1040$ chip and a Polychromator V (Till Photonics, Gräfelfing, Germany) that was coupled via an optical fiber into the Zeiss AxioExaminer upright microscope (Objective W "Plan-Apochromat" 20x/1.0 DIC $\mathrm{D}=0.17 \mathrm{M} 2775 \mathrm{~mm}$ ). The camera and polychromator were controlled by the software Zen pro, including the module 'Physiology' (2012 blue edition, Zeiss). The DRV neurons were identified according to their anatomical location and expression of the GCaMP6. Calcium signals in GCaMP6 expressing cells were monitored by images acquired at $470 \mathrm{~nm}$ excitation wavelengths with $80 \mathrm{~ms}$ exposure time at $\sim 0.2 \mathrm{~Hz}$. The emitted fluorescence was detected through a $500-550 \mathrm{~nm}$ bandpass filter (BP525/50), and data were acquired using $4 \times 4$ on-chip binning.

Orexin A and orexin B were applied for 10 min as described for electrophysiology. To analyze the orexin effect, we compared the fluorescence measured during 4 min intervals that were recorded immediately before and at the end of the peptide application. This protocol was followed by applying high $\mathrm{K}^{+}$ concentration saline $(40 \mathrm{mM} \mathrm{KCl}$; osmolarity was adjusted by reducing the $\mathrm{NaCl}$ concentration accordingly) to elicit the maximal calcium response.

The image analysis was performed offline using Image J (version 1.53a) Igor Pro 6 and Prism 8 (GraphPad, California, USA). After the experiments, regions of interest (ROI) were defined, based on the high $\mathrm{K}^{+}$saline responses. The mean $\mathrm{AU}$ values of the ROIs were calculated in Image J. Time series analysis was performed with Igor Pro 6. To correct for bleaching artifacts, the baseline fluorescence (without orexin application) was fit. The extended fit was subtracted from the raw data. The orexin-induced $\mathrm{Ca}^{2+}$ signals are given relative to the high $\mathrm{K}^{+}$response.

Data analysis of electrophysiological and $\mathbf{C a}^{2+}$ imaging data. Data analysis was performed with Spike2 (version 7; Cambridge Electronic Design Ltd., Cambridge, UK), Igor Pro 6 (Wavemetrics, Portland, OR, USA), and Graphpad Prism 8. If not stated otherwise, all calculated values are expressed as means \pm SEM (standard error of the mean). The horizontal lines show the data's median. The whiskers were calculated according to the 'Tukey' method. For pairwise comparisons of dependent normal distributions, paired t-tests were used. For multiple comparisons, ANOVA with post hoc Tukey tests was performed. Tests were executed using GraphPad Prism 8. A significance level of 0.05 was accepted for all tests. Exact $p$ values are reported if $p>0.05$. In the figures, $n$ values are given in brackets. 
The orexin effects were analyzed by comparing the action potential frequencies that were measured during 2 min intervals that were recorded before and at the end of the peptide applications. To analyze the orexin responsiveness, the neuron's firing rate averaged from $10 \mathrm{~s}$ intervals was taken as one data point. To determine the mean firing rate and standard deviation, 12 data points were averaged. On the single-cell level, a neuron was considered orexin-responsive if the change in firing induced by orexin was three times larger than the standard deviation (SD $)^{80,81}$.

General statistical methods. If not stated otherwise, all values are expressed as the mean \pm SEM (standard error of the mean). Statistical analyses were conducted using GraphPad Prism 8. unless stated otherwise. Datasets with only two independent groups were analyzed for statistical significance using an unpaired two-tailed Student's $t$ test, and paired two-tailed $t$-test was used when data were matched. Datasets subjected to two independent factors were analyzed using two-way ANOVA followed by Sidak's post hoc test, if not stated otherwise. All $p$-values $<0.05$ were considered significant

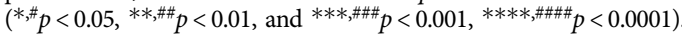

Reporting summary. Further information on research design is available in the Nature Research Reporting Summary linked to this article.

\section{Data availability}

The RNA-Seq data generated in this study have been deposited in the GEO database under accession code GSE168203. The source data underlying Figs. lc-i, k-m, 2e-h, 3b, c, e, 4b-r, 5a-f, 6a-f, 7c-l, n-p, 8b, d, e, g, 9d, e, g and Supplementary Figs. 1j, n, o, p, r, 3c, 4a-h, 5a-f, $6 \mathrm{a}, \mathrm{b}, 9 \mathrm{a}-\mathrm{d}, \mathrm{f}$ are provided as a Source Data file. Raw data that support the findings of this study are available from the corresponding author upon reasonable request. Publicly available datasets used in this study include GRCm38 dataset (https://www.ncbinlm.nih.gov/assembly/ GCF_000001635.20) and "scRNA-seq_huang2019" (https://doi.org/10.7910/DVN/QB5CC8). There are no restrictions on data availability. Source data are provided with this paper.

\section{Code availability}

The source code for analysing the RNA-Seq data presented in this study are deposited on GitHub with the repository bruening-lab/Sert-Ox1R (https://github.com/bruening-lab/ Sert-Ox1R). There are no restrictions on code availability.

Received: 3 November 2020; Accepted: 5 August 2021; Published online: 02 September 2021

\section{References}

1. Ng, M. et al. Global, regional, and national prevalence of overweight and obesity in children and adults during 1980-2013: a systematic analysis for the Global Burden of Disease Study 2013. Lancet 384, 766-781 (2014).

2. Timper, K. \& Bruning, J. C. Hypothalamic circuits regulating appetite and energy homeostasis: pathways to obesity. Dis. Model Mech. 10, 679-689 (2017).

3. Soya, S. \& Sakurai, T. Evolution of orexin neuropeptide system: structure and function. Front. Neurosci. 14, 691 (2020).

4. Sakurai, T. et al. Orexins and orexin receptors: a family of hypothalamic neuropeptides and $\mathrm{G}$ protein-coupled receptors that regulate feeding behavior. Cell 92, 573-585 (1998).

5. de Lecea, L. et al. The hypocretins: hypothalamus-specific peptides with neuroexcitatory activity. Proc. Natl Acad. Sci. USA 95, 322-327 (1998).

6. Doherty, M. J., Watson, N. F., Hallam, D. K., Chandler, W. L. \& Longstreth, W. T. Ventricular cerebrospinal fluid hypocretin-I inversely correlates with glucose levels in cerebrospinal fluid and serum from patients with neurological injuries. Neurocritical Care 3, 230-233 (2005).

7. Nishino, S. et al. Low cerebrospinal fluid hypocretin (orexin) and altered energy homeostasis in human narcolepsy. Ann. Neurol. 50, 381-388 (2001).

8. Hara, J. et al. Genetic ablation of orexin neurons in mice results in narcolepsy, hypophagia, and obesity. Neuron 30, 345-354 (2001).

9. Tabuchi, S. et al. Conditional ablation of orexin/hypocretin neurons: a new mouse model for the study of narcolepsy and orexin system function. $J$. Neurosci. 34, 6495-6509 (2014).

10. Funato, H. et al. Enhanced orexin receptor-2 signaling prevents diet-induced obesity and improves leptin sensitivity. Cell Metab. 9, 64-76 (2009).

11. Inutsuka, A. et al. Concurrent and robust regulation of feeding behaviors and metabolism by orexin neurons. Neuropharmacology 85, 451-460 (2014).

12. Adamantidis, A. R., Zhang, F., Aravanis, A. M., Deisseroth, K. \& de Lecea, L. Neural substrates of awakening probed with optogenetic control of hypocretin neurons. Nature 450, 420-424 (2007).

13. Tsuneki, H., Wada, T. \& Sasaoka, T. Role of orexin in the central regulation of glucose and energy homeostasis. Endocr. J. 59, 365-374 (2012).
14. Tsuneki, H. et al. Hypothalamic orexin prevents hepatic insulin resistance via daily bidirectional regulation of autonomic nervous system in mice. Diabetes 64, 459-470 (2015)

15. Kakizaki, M. et al. Differential roles of each orexin receptor signaling in obesity. iScience 20, 1-13 (2019).

16. Marcus, J. N. et al. Differential expression of orexin receptors 1 and 2 in the rat brain. J. Comp. Neurol. 435, 6-25 (2001).

17. Cluderay, J. E., Harrison, D. C. \& Hervieu, G. J. Protein distribution of the orexin-2 receptor in the rat central nervous system. Regul. Pept. 104, 131-144 (2002).

18. Hervieu, G. J., Cluderay, J. E., Harrison, D. C., Roberts, J. C. \& Leslie, R. A. Gene expression and protein distribution of the orexin-1 receptor in the rat brain and spinal cord. Neuroscience 103, 777-797 (2001).

19. Lu, X. Y., Bagnol, D., Burke, S., Akil, H. \& Watson, S. J. Differential distribution and regulation of OX1 and OX2 orexin/hypocretin receptor messenger RNA in the brain upon fasting. Horm. Behav. 37, 335-344 (2000).

20. Okaty, B. W. et al. Multi-scale molecular deconstruction of the serotonin neuron system. Neuron 88, 774-791 (2015).

21. Calizo, L. H. et al. Raphe serotonin neurons are not homogenous: electrophysiological, morphological and neurochemical evidence. Neuropharmacology 61, 524-543 (2011).

22. Lesch, K. P., Araragi, N., Waider, J., van den Hove, D. \& Gutknecht, L. Targeting brain serotonin synthesis: insights into neurodevelopmental disorders with long-term outcomes related to negative emotionality, aggression and antisocial behaviour. Philos. Trans. R. Soc. Lond. B Biol. Sci. 367, 2426-2443 (2012)

23. Marston, O. J., Garfield, A. S. \& Heisler, L. K. Role of central serotonin and melanocortin systems in the control of energy balance. Eur. J. Pharm. 660, 70-79 (2011).

24. Lam, D. D., Garfield, A. S., Marston, O. J., Shaw, J. \& Heisler, L. K. Brain serotonin system in the coordination of food intake and body weight. Pharm. Biochem Behav. 97, 84-91 (2010).

25. Liu, Z. et al. Dorsal raphe neurons signal reward through 5-HT and glutamate. Neuron 81, 1360-1374 (2014).

26. Donovan, M. H. \& Tecott, L. H. Serotonin and the regulation of mammalian energy balance. Front. Neurosci. 7, 36 (2013).

27. McGlashon, J. M. et al. Central serotonergic neurons activate and recruit thermogenic brown and beige fat and regulate glucose and lipid homeostasis. Cell Metab. 21, 692-705 (2015).

28. Tupone, D., Madden, C. J., Cano, G. \& Morrison, S. F. An orexinergic projection from perifornical hypothalamus to raphe pallidus increases rat brown adipose tissue thermogenesis. J. Neurosci. 31, 15944-15955 (2011).

29. Madisen, L. et al. A robust and high-throughput Cre reporting and characterization system for the whole mouse brain. Nat. Neurosci. 13, 133-140 (2010).

30. Huang, K. W. et al. Molecular and anatomical organization of the dorsal raphe nucleus. Elife 8, e46464 (2019).

31. Huang, K. W. "scRNA-seq_huang2019", https://doi.org/10.7910/DVN/ QB5CC8, Harvard Dataverse, V1 (2019).

32. Kohlmeier, K. A., Watanabe, S., Tyler, C. J., Burlet, S. \& Leonard, C. S. Dual orexin actions on dorsal raphe and laterodorsal tegmentum neurons: noisy cation current activation and selective enhancement of $\mathrm{Ca}_{2}{ }^{+}$transients mediated by L-type calcium channels. J. Neurophysiol. 100, 2265-2281 (2008).

33. Liu, R. J., Van Den Pol, A. N. \& Aghajanian, G. K. Hypocretins (orexins) regulate serotonin neurons in the dorsal raphe nucleus by excitatory direct and inhibitory indirect actions. J. Neurosci. 22, 9453-9464 (2002).

34. Brown, R. E., Sergeeva, O. A., Eriksson, K. S. \& Haas, H. L. Convergent excitation of dorsal raphe serotonin neurons by multiple arousal systems (orexin/hypocretin, histamine and noradrenaline). J. Neurosci. 22, 8850-8859 (2002).

35. Berger, M., Gray, J. A. \& Roth, B. L. The expanded biology of serotonin. Annu. Rev. Med. 60, 355-366 (2009).

36. Haj-Dahmane, S. \& Shen, R.-Y. The wake-promoting peptide orexin-B inhibits glutamatergic transmission to dorsal raphe nucleus serotonin neurons through retrograde endocannabinoid signaling. J. Neurosci. 25, 896-905 (2005).

37. Brown, R. E., Sergeeva, O., Eriksson, K. S. \& Haas, H. L. Orexin A excites serotonergic neurons in the dorsal raphe nucleus of the rat. Neuropharmacology 40, 457-459 (2001).

38. Matsuki, T. \& Sakurai, T. Orexins and orexin receptors: from molecules to integrative physiology. Results Probl. Cell Differ. 46, 27-55 (2008).

39. McGregor, R. A. et al. Time-course microarrays reveal modulation of developmental, lipid metabolism and immune gene networks in intrascapular brown adipose tissue during the development of diet-induced obesity. Int $J$. Obes. 37, 1524-1531 (2013).

40. Wolf, Y. et al. Brown-adipose-tissue macrophages control tissue innervation and homeostatic energy expenditure. Nat. Immunol. 18 665-674 (2017). 
41. Roh, H. C. et al. Warming induces significant reprogramming of beige, but not brown, adipocyte cellular identity. Cell Metab. 27, 1121-1137 (2018). e1125.

42. Brestoff, J. R. \& Artis, D. Immune regulation of metabolic homeostasis in health and disease. Cell 161, 146-160 (2015).

43. Lahera, V., de las Heras, N., López-Farré, A., Manucha, W. \& Ferder, L. Role of mitochondrial dysfunction in hypertension and obesity. Curr. Hypertens. Rep. 1-9 (2017).

44. Youle, R. J. \& van der Bliek, A. M. Mitochondrial fission, fusion, and stress. Science 337, 1062-1065 (2012).

45. Schrepfer, E. \& Scorrano, L. Mitofusins, from mitochondria to metabolism. Mol. Cell 61, 683-694 (2016).

46. Sellayah, D., Bharaj, P. \& Sikder, D. Orexin Is required for brown adipose tissue development, differentiation, and function. Cell Metab. 14, 478-490 (2011).

47. Shiuchi, T. et al. Hypothalamic orexin stimulates feeding-associated glucose utilization in skeletal muscle via sympathetic nervous system. Cell Metab. 10, 466-480 (2009).

48. Alenina, N. et al. Growth retardation and altered autonomic control in mice lacking brain serotonin. Proc. Natl Acad. Sci. USA 106, 10332-10337 (2009).

49. Ferguson, A. V. \& Samson, W. K. The orexin/hypocretin system: a critical regulator of neuroendocrine and autonomic function. Front. Neuroendocrinol. 24, 141-150 (2003).

50. Hale, M. W. \& Lowry, C. A. Functional topography of midbrain and pontine serotonergic systems: implications for synaptic regulation of serotonergic circuits. Psychopharmacology 213, 243-264 (2011).

51. Ren, J. et al. Anatomically defined and functionally distinct dorsal raphe serotonin sub-systems. Cell 175, 472-487 (2018). e420.

52. Amilhon, B. et al. VGLUT3 (vesicular glutamate transporter type 3) contribution to the regulation of serotonergic transmission and anxiety. $J$. Neurosci. 30, 2198-2210 (2010).

53. Nectow, A. R. et al. Identification of a brainstem circuit controlling feeding. Cell 170, 429-442 (2017). e411.

54. Pollak Dorocic, I. et al. A whole-brain atlas of inputs to serotonergic neurons of the dorsal and median raphe nuclei. Neuron 83, 663-678 (2014).

55. Ogawa, S. K., Cohen, J. Y., Hwang, D., Uchida, N. \& Watabe-Uchida, M. Organization of monosynaptic inputs to the serotonin and dopamine neuromodulatory systems. Cell Rep. 8, 1105-1118 (2014).

56. Lechin, F., van der Dijs, B. \& Hernández-Adrián, G. Dorsal raphe vs. median raphe serotonergic antagonism. Anatomical, physiological, behavioral, neuroendocrinological, neuropharmacological and clinical evidences: relevance for neuropharmacological therapy. Prog. Neuro-Psychopharmacol. Biol. Psychiatry 30, 565-585 (2006).

57. Teissier, A. et al. Activity of raphe serotonergic neurons controls emotional behaviors. Cell Rep. 13, 1965-1976 (2015).

58. Gong, S. et al. A gene expression atlas of the central nervous system based on bacterial artificial chromosomes. Nature 425, 917-925 (2003).

59. Madisen, L. et al. A toolbox of Cre-dependent optogenetic transgenic mice for light-induced activation and silencing. Nat. Neurosci. 15, 793-802 (2012)

60. Rodriguez, C. I. et al. High-efficiency deleter mice show that FLPe is an alternative to Cre-loxP. Nat. Genet. 25, 139-140 (2000)

61. Lee, E. C. et al. A highly efficient Escherichia coli-based chromosome engineering system adapted for recombinogenic targeting and subcloning of BAC DNA. Genomics 73, 56-65 (2001).

62. Jais, A. et al. Heme oxygenase-1 drives metaflammation and insulin resistance in mouse and man. Cell 158, 25-40 (2014)

63. Ewels, P., Hammarén, R., Peltzer, A., Moreno, D. \& Wang, C. nf-core/rnaseq: nf-core/rnaseq version 1.4 "Gray Crocus Dachshund". Zenodo (2019).

64. Patro, R., Duggal, G., Love, M. I., Irizarry, R. A. \& Kingsford, C. Salmon provides fast and bias-aware quantification of transcript expression. Nat. Methods 14, 417-419 (2017).

65. Love, M. I., Huber, W. \& Anders, S. Moderated estimation of fold change and dispersion for RNA-seq data with DESeq2. Genome Biol. 15, 550 (2014).

66. Yu, G., Wang, L.-G., Han, Y. \& He, Q.-Y. clusterProfiler: an R package for comparing biological themes among gene clusters. OMICS: A J. Integr. Biol. 16, 284-287 (2012)

67. Jordan, S. D. et al. Obesity-induced overexpression of miRNA-143 inhibits insulin-stimulated AKT activation and impairs glucose metabolism. Nat. Cell Biol. 13, 434-446 (2011).

68. Konner, A. C. et al. Insulin action in AgRP-expressing neurons is required for suppression of hepatic glucose production. Cell Metab. 5, 438-449 (2007).

69. Ferre, P., Leturque, A., Burnol, A. F., Penicaud, L. \& Girard, J. A method to quantify glucose utilization in vivo in skeletal muscle and white adipose tissue of the anaesthetized rat. Biochem. J. 228, 103-110 (1985).

70. Franklin, K. B. J. \& Paxinos, G. The Mouse Brain in Stereotaxic Coordinates. 3rd edn. (Elsevier/Academic Press, 2007).
71. Lin, J. Y., Lin, M. Z., Steinbach, P. \& Tsien, R. Y. Characterization of engineered channelrhodopsin variants with improved properties and kinetics. Biophys. J. 96, 1803-1814 (2009).

72. Ye, J. H., Zhang, J., Xiao, C. \& Kong, J. Q. Patch-clamp studies in the CNS illustrate a simple new method for obtaining viable neurons in rat brain slices: glycerol replacement of $\mathrm{NaCl}$ protects CNS neurons. J. Neurosci. Methods 158 251-259 (2006).

73. Hess, M. E. et al. The fat mass and obesity associated gene (Fto) regulates activity of the dopaminergic midbrain circuitry. Nat. Neurosci. 16, 1042-1048 (2013).

74. Konner, A. C. et al. Role for insulin signaling in catecholaminergic neurons in control of energy homeostasis. Cell Metab. 13, 720-728 (2011).

75. Dodt, H. U. \& Zieglgansberger, W. Visualizing unstained neurons in living brain slices by infrared DIC-videomicroscopy. Brain Res. 537, 333-336 (1990).

76. Akaike, N. \& Harata, N. Nystatin perforated patch recording and its applications to analyses of intracellular mechanisms. Jpn J. Physiol. 44, 433-473 (1994).

77. Horn, R. \& Marty, A. Muscarinic activation of ionic currents measured by a new whole-cell recording method. J. Gen. Physiol. 92, 145-159 (1988).

78. Lindau, M. \& Fernandez, J. M. IgE-mediated degranulation of mast cells does not require opening of ion channels. Nature 319, 150-153 (1986).

79. Rae, J., Cooper, K., Gates, P. \& Watsky, M. Low access resistance perforated patch recordings using amphotericin-B. J. Neurosci. Methods 37, 15-26 (1991).

80. Dhillon, $\mathrm{H}$. et al. Leptin directly activates SF1 neurons in the VMH, and this action by leptin is required for normal body-weight homeostasis. Neuron 49 , 191-203 (2006).

81. Kloppenburg, P., Zipfel, W. R., Webb, W. W. \& Harris-Warrick, R. M. Heterogeneous effects of dopamine on highly localized, voltage-induced $\mathrm{Ca}^{2+}$ accumulation in identified motoneurons. J. Neurophysiol. 98, 2910-2917 (2007).

\section{Acknowledgements}

We acknowledge Hella Brönneke for outstanding support; Jens Alber, Andreas Beyrau, Nadine Evers, Brigitte Hampel, Pia Scholl, Christiane Schäfer, Nadine Spenrath, Christian Heilinger, Helmut Wratil, and Kerstin Marohl for outstanding technical assistance; and Janine Altmüller and Marek Franitza from Cologne Center for Genomics for excellent technical assistance with RNA-seq, as well as Beatrix Martiny from CECAD Imaging Facility Cologne for excellent technical assistance with electron microscopy. We thank Dr. Henning Fenselau for critically reading the manuscript. This work was supported by a grant from the Deutsche Forschungsgemeinschaft (DFG) (BR 1492/7-1) to J.C.B., and we received funding by the DFG within the framework of the TRR 134 (A.C.H., J.C.B., P. Kloppenburg, F.T.W.) and within the Excellence Initiative by German Federal and State Governments (CECAD). X.X. received funding of CECAD family support. This work was funded (in part) by the Helmholtz Alliance ICEMED (Imaging and Curing Environmental Metabolic Diseases) through the Initiative and Networking Fund of the Helmholtz Association. Moreover, the research leading to these results has received funding from the European Union Seventh Framework Program (FP7/ 2007-2013) under grant agreement 266408. G.Y. gratefully acknowledges financial doctoral support from the DFG-233886668/GRK1960. B.B.L. is supported by the US National Institute of Health (NIH; R01 DK075632, R01 DK089044, R01 DK096010, R01 DK111401, P30 DK046200, and P30 DK057521). D.K. is supported by NIH (R01 NS107315, R01 DK108797, R21 HD098056, P30 DK046200). K.R. is supported by NIH (HL084207), the Department of Veterans Affairs (Merit grant BX004249), the University of Iowa Fraternal Order of Eagles Diabetes Research Center and the Iowa Neuroscience Institute.

\section{Author contributions}

X.X., A.C.H., and J.C.B. conceived the project, designed the experiments, analyzed the data, and wrote the manuscript with input from the other authors. A.K. and F.T.W. designed the targeting strategy for conditional Ox1R flox mice and Ox2R flox mice and A.C.H. generated the mouse lines. B.B.L., T.E.S., and D.K. generated the Orexin-Cre mice. X.X. performed all the experiments apart from hyperinsulinemic-euglycemic clamp experiments (X.X., A.S., and A.C.H.), $\mathrm{Ca}^{2+}$ imaging (G.Y. and P. Kloppenburg) and electrophysiological recordings (S.H., G.Y., and P. Kloppenburg). P. Klemm performed RNA sequencing data analysis. D.A.M. and K.R. helped with the design of BAT experiments, writing of the manuscript, and provided technical guidance. All authors discussed the data, commented on the manuscript before submission, and agreed with the final submitted manuscript

\section{Funding}

Open Access funding enabled and organized by Projekt DEAL.

\section{Competing interests}

The authors declare no competing interests. 


\section{Additional information}

Supplementary information The online version contains supplementary material available at https://doi.org/10.1038/s41467-021-25380-2.

Correspondence and requests for materials should be addressed to A.C.H.

Peer review information Nature Communications thanks Takeshi Sakurai and the other anonymous reviewer(s) for their contribution to the peer review of this work. Peer reviewer reports are available.

Reprints and permission information is available at http://www.nature.com/reprints

Publisher's note Springer Nature remains neutral with regard to jurisdictional claims in published maps and institutional affiliations. (c) (i) Open Access This article is licensed under a Creative Commons Attribution 4.0 International License, which permits use, sharing, adaptation, distribution and reproduction in any medium or format, as long as you give appropriate credit to the original author(s) and the source, provide a link to the Creative Commons license, and indicate if changes were made. The images or other third party material in this article are included in the article's Creative Commons license, unless indicated otherwise in a credit line to the material. If material is not included in the article's Creative Commons license and your intended use is not permitted by statutory regulation or exceeds the permitted use, you will need to obtain permission directly from the copyright holder. To view a copy of this license, visit http://creativecommons.org/ licenses/by/4.0/.

(C) The Author(s) 2021 